\title{
Modulation of thalamocortical oscillations by TRIP8b, an auxiliary subunit for HCN channels
}

\author{
Mehrnoush Zobeiri ${ }^{1}$ (1) $\cdot$ Rahul Chaudhary ${ }^{1} \cdot$ Maia Datunashvili $^{1} \cdot$ Robert J. Heuermann $^{2}$ • \\ Annika Lüttjohann ${ }^{1} \cdot$ Venu Narayanan $^{3} \cdot$ Sabine Balfanz $^{4} \cdot$ Patrick Meuth $^{1}$. \\ Dane M. Chetkovich ${ }^{2}$ Hans-Christian Pape ${ }^{1} \cdot$ Arnd Baumann $^{4} \cdot$ Gilles van Luijtelaar $^{5}$. \\ Thomas Budde ${ }^{1}$
}

Received: 30 May 2017/ Accepted: 30 October 2017/Published online: 22 November 2017

(c) The Author(s) 2017. This article is an open access publication

\begin{abstract}
Hyperpolarization-activated cyclic nucleotidegated cation $(\mathrm{HCN})$ channels have important functions in controlling neuronal excitability and generating rhythmic oscillatory activity. The role of tetratricopeptide repeatcontaining Rab8b-interacting protein (TRIP8b) in regulation of hyperpolarization-activated inward current, $I_{\mathrm{h}}$, in the thalamocortical system and its functional relevance for the physiological thalamocortical oscillations were investigated. A significant decrease in $I_{\mathrm{h}}$ current density, in both thalamocortical relay (TC) and cortical pyramidal neurons was found in TRIP8b-deficient mice (TRIP8b ${ }^{-1-}$ ). In addition basal cAMP levels in the brain were found to be decreased while the availability of the fast transient A-type $\mathrm{K}^{+}$current, $I_{\mathrm{A}}$, in TC neurons was increased. These
\end{abstract}

Electronic supplementary material The online version of this article (https://doi.org/10.1007/s00429-017-1559-z) contains supplementary material, which is available to authorized users.

Mehrnoush Zobeiri

zobeiri@uni-muenster.de

$\triangle$ Thomas Budde

tbudde@uni-muenster.de

1 Institut für Physiologie I, Westfälische Wilhelms-Universität, 48149 Münster, Germany

2 Davee Department of Neurology and Clinical Neurosciences and Department of Physiology, Feinberg School of Medicine, Northwestern University, 60611Chicago, USA

3 Department of Neurology and Institute of Translational Neurology, Westfälische Wilhelms-Universität, 48149 Münster, Germany

4 Institute of Complex Systems, Zelluläre Biophysik (ICS-4), Forschungszentrum Jülich, 52425 Jülich, Germany

5 Donders Centre for Cognition, Radboud University, 6500 Nijmegen, The Netherlands changes were associated with alterations in intrinsic properties and firing patterns of TC neurons, as well as intrathalamic and thalamocortical network oscillations, revealing a significant increase in slow oscillations in the delta frequency range $(0.5-4 \mathrm{~Hz})$ during episodes of active-wakefulness. In addition, absence of TRIP8b suppresses the normal desynchronization response of the EEG during the switch from slow-wave sleep to wakefulness. It is concluded that TRIP8b is necessary for the modulation of physiological thalamocortical oscillations due to its direct effect on HCN channel expression in thalamus and cortex and that mechanisms related to reduced cAMP signaling may contribute to the present findings.

Keywords Delta oscillations - Thalamocortical oscillations · TRIP8b · HCN channels · Knockout mice $\cdot$ In vivo $\cdot I_{\mathrm{A}}$

\section{Introduction}

The excitability of thalamic neurons is regulated by a number of peculiar ionic conductances generated by different voltage-gated ion channels such as low-threshold (Ttype) $\mathrm{Ca}^{2+}$ channels (carrying $I_{\mathrm{T}}$ ), hyperpolarization-activated cyclic nucleotide-gated $(\mathrm{HCN})$ channels (carrying the hyperpolarization-activated cation current, $I_{\mathrm{h}}$ ) and leak $\mathrm{K}^{+}$channels which are the basis for the thalamic contribution in the genesis of EEG electroencephalogram delta waves during slow wave sleep (Sherman 2005; Timofeev and Bazhenov 2005; Bista et al. 2015a; Curró Dossi et al. 1992). Recurring interactions of these ionic conductances play an important role in the generation of single cell as well as network oscillations. In the absence of external synaptic inputs, for instance, TC neurons show a pattern of 
intrinsic rhythmic activity composed of bursts of action potentials (APs) at a frequency of $0.5-4 \mathrm{~Hz}$ (delta oscillations). The delta frequency rhythm in a single thalamocortical neuron is driven by the interplay of $I_{\mathrm{h}}$ and $I_{\mathrm{T}}$ (the latter is activated by $I_{\mathrm{h}}$-dependent depolarization). Synchronization of intrinsic membrane oscillations through synaptic mechanisms then leads to the network activities which characterize sleep and wake patterns of the EEG (McCormick and Bal 1997; Steriade et al. 1993; McCormick and Pape 1990).

Four HCN channel isoforms (HCN1-4) are the molecular basis of $I_{\mathrm{h}}$, which is inwardly directed at rest, and therefore, depolarizes the resting membrane potential (RMP). This current is involved in basic to more complex neuronal functions such as regulation of RMP, synaptic transmission, dendritic integration, initiation and control of rhythmic activity in neuronal circuits and contribution to subthreshold membrane potential oscillations (Wahl-Schott and Biel 2009; He et al. 2014). In fact, the role of $I_{\mathrm{h}}$ in the generation of single cell and synchronized network oscillations in the thalamocortical system during sleep and sensory processing has been analyzed in several studies (He et al. 2014; McCormick et. al 1992; McCormick and Pape 1990; Steriade et al. 1993; Wahl-Schott and Biel 2009; Llinas and Steriade 2006; Steriade and Deschenes 1984; Sherman and Guillery 2002; Kanyshkova et al. 2009; Curró Dossi et al. 1992). Dysregulation of $I_{\mathrm{h}}$ has been reported to play a role in some pathophysiological conditions including epileptic seizures and neuropathic pain (Herrmann et al. 2007; Kanyshkova et al. 2012; Wemhöner et al. 2015). The function of $\mathrm{HCN}$ channels is fine-tuned by several molecular factors. The modulatory role of these molecules is conveyed via direct effects on channels gating and/or through expression changes of the channel proteins. TRIP8b, also known as PEX5R and PEX5Rp, is a brainspecific auxiliary subunit for $\mathrm{HCN}$ channels which has been relatively recently discovered. Several different splice variants of TRIP8b have been uncovered which can differentially control the gating, surface expression and trafficking of HCN channel subunits in a subtype-specific manner (Santoro et al. 2004; Lewis et al. 2009; Santoro et al. 2009; Piskorowski et al. 2011; Huang et al. 2012). However, not much is known about the functional role of TRIP8b in physiological thalamocortical oscillations. A recent study (Heuermann et al. 2016) revealed that the complete loss of TRIP8b is associated with profound reduction of $I_{\mathrm{h}}$ and an absence epileptic phenotype thereby revealing pathophysiological thalamocortical activity. However, the effect of TRIP8b-deficiency on physiological oscillations in the thalamocortical system during natural sleep and wakefulness has not been addressed.

The aim of the present study was, therefore, to determine possible thalamus-related changes in brain rhythms, especially delta activity, by performing local field potential (LFP) recordings on freely moving TRIP8b ${ }^{-1-}$ and wildtype control mice in vivo. Since the occurrence of delta oscillations in the EEG critically depend on the maturation and properties of thalamic $I_{\mathrm{h}}$ (Kanyshkova et al. 2009), we analyzed this current in different thalamic nuclei. In addition, intrathalamic oscillations were investigated by performing LFP recordings in horizontal thalamic slices. Computer modeling approaches were used to assess the effects of graded changes in $I_{\mathrm{h}}$ on intrathalamic and thalamocortical oscillations. We found that the loss of TRIP8b induced a reduction of $I_{\mathrm{h}}$ in thalamic neurons which, in combination with reduced basal cAMP levels and increased $I_{\mathrm{A}}$, was associated with hyperpolarization of the membrane potential, increased bursting, slowed thalamocortical oscillations and increased delta activity during states of active-wakefulness thereby characterizing the TRIP8b-deficiency as thalamocortical dysrhythmia.

\section{Materials and methods}

Mice with total elimination of TRIP8b in the brain, termed TRIP8b $^{-l-}$ mice here, were obtained from the original colony at Davee Department of Neurology and Clinical Neurosciences and Department of Physiology (Northwestern University, Chicago, USA) and transferred to the Institute of Physiology I (Westfälische Wilhelms-Universität, Münster, Germany). Animals were three times backcrossed with C57BL/6J mice (Harlan Laboratories, Nienburg, Germany) and kept as knockout strain thereafter. As before (Lewis et al. 2011), C57BL/6J mice were used as controls (termed as wild-type, WT, in the following). All experimental procedures were performed in accordance with the principles approved by local authorities (review board institution: Landesamt für Natur, Umwelt und Verbraucherschutz Nordrhein-Westfalen; Approval IDs: 84-02.04.2015.A574, 84-02.05.50.15.026). Efforts were made to minimize the number of animals and the degree of discomfort to animals used in this study.

\section{Preparation of acute brain slices for patch-clamp recordings}

Animals were sacrificed under isoflurane anesthesia and brain tissue was rapidly removed from the skull. Thalamic and cortical coronal slices $(250 \mu \mathrm{m})$ were prepared from TRIP8b $^{-1-}$ and WT mice of different ages (p15-30 and p90-120) in ice-cold oxygenated $\left(\mathrm{O}_{2}\right)$ slicing solution, containing (in $\mathrm{mM}$ ): sucrose, 200; PIPES, 20; $\mathrm{KCl}, 2.5$; $\mathrm{NaH}_{2} \mathrm{PO}_{4}, 1.25 ; \mathrm{MgSO}_{4}, 10 ; \mathrm{CaCl}_{2}, 0.5$; dextrose, $10 ; \mathrm{pH}$ 7.35 , with $\mathrm{NaOH}$. Slices were transferred to and kept in a chamber with artificial cerebrospinal fluid (ACSF) 
containing (in mM): $\mathrm{NaCl}, 120 ; \mathrm{KCl}, 2.5 ; \mathrm{NaH}_{2} \mathrm{PO}_{4}, 1.25$; $\mathrm{NaHCO}_{3}, 22 ; \mathrm{MgSO}_{4}, 2 ; \mathrm{CaCl}_{2}, 2$; glucose, 25. Temperature was set to $33{ }^{\circ} \mathrm{C}$ for $30 \mathrm{~min}$ and slices were allowed to cool down to room temperature thereafter. $\mathrm{pH}$ was adjusted to 7.35 by bubbling with carbogen $\left(95 \% \mathrm{O}_{2}\right.$ and $\left.5 \% \mathrm{CO}_{2}\right)$.

\section{Patch-clamp recordings in acute brain slices}

$I_{\mathrm{h}}$ was characterized by whole-cell patch-clamp recordings from TC neurons of the ventrobasal complex (VB), posterior thalamic nucleus (PO), central-medial nucleus (CM) and the dorsal part of the lateral geniculate nucleus (dLGN), as well as pyramidal neurons in layer V and VI of the somatosensory cortex. Recordings were carried out in an external solution (bath solution) containing (in $\mathrm{mM}$ ): $\mathrm{NaCl}, 125 ; \mathrm{KCl}, 2.5 ; \mathrm{NaH}_{2} \mathrm{PO}_{4}, 1.25 ;$ HEPES, 30; $\mathrm{MgSO}_{4}$, 2; $\mathrm{CaCl}_{2}, 2$; Glucose, 10; $\mathrm{BaCl}_{2}, 0.5-1$ (only added in voltage-clamp recordings); $\mathrm{pH} 7.35$, at $30 \pm 1{ }^{\circ} \mathrm{C}$. Patch pipettes were pulled from borosilicate glass (GC150T-10; Clark Electromedical Instruments, Pangbourne, UK) and had a resistance of 3-4 M . The internal solution (pipette solution) contained (in $\mathrm{mM}$ ): K-gluconate, $88 ; \mathrm{K}_{3}$-citrate, 20; $\mathrm{NaCl}, 10$; HEPES, $10 ; \mathrm{MgCl}_{2}, 1 ; \mathrm{CaCl}_{2}, 0.5$; BAPTA, 3; Mg-ATP, 3; $\mathrm{Na}_{2}$-GTP, 0.5. The internal solution was set to a $\mathrm{pH}$ of 7.25 with $\mathrm{KOH}$ and an osmolality of 295 $\mathrm{mOsmol} / \mathrm{kg}$. All recordings were performed on the soma of TC or cortical pyramidal neurons using an EPC 10 amplifier (HEKA Elektronik, Lamprecht, Germany). The access resistance was in a range of 5-25 M $\Omega$ and was monitored throughout the experiment. Cells with access resistance more than $25 \mathrm{M} \Omega$ were discarded from the experiment. Series resistance compensation of $>30 \%$ was routinely applied. Voltage-clamp experiments were controlled by the software PatchMaster (HEKA Elektronik) operating on an IBM-compatible personal computer. All measurements were corrected offline for a liquid junction potential of $10 \mathrm{mV}$.

For voltage clamp recordings of $\mathrm{K}^{+}$outward currents the extracellular solution contained $(\mathrm{mM}): \mathrm{NaCl}, 125 ; \mathrm{KCl}$, 2; HEPES, 10; Glucose, 10; $\mathrm{MgCl}_{2}$, 4. For isolation of $I_{\mathrm{A}}$, TTX $(1 \mu \mathrm{M})$ and tetraethylammonium (TEA-Cl, $10 \mathrm{mM})$ were added to the recording solution. $\mathrm{CaCl}_{2}$ was replaced by an equimolar concentration of $\mathrm{MgCl}_{2}$ and residual-free extracellular $\mathrm{Ca}^{2+}$ was chelated by adding EGTA $(1 \mathrm{mM})$. The intracellular solution contained: $\mathrm{NaCl} 10, \mathrm{KCl} 10$, K-gluconate, 88; $\mathrm{K}_{3}$-citrate, 20; $\mathrm{NaCl}, 10$; HEPES, 10; $\mathrm{MgCl}_{2}, 1 ; \mathrm{CaCl}_{2}, 0.5$; BAPTA, 3; Mg-ATP, 3; $\mathrm{Na}_{2}$-GTP, 0.5 . The internal solution was set to a $\mathrm{pH}$ of 7.25 with $\mathrm{KOH}$ and an osmolality of $295 \mathrm{mOsmol} / \mathrm{kg}$. A liquid junction potential of $19 \mathrm{mV}$ was taken into account here.

\section{Voltage-clamp recordings}

The protocol used for assessment of $I_{\mathrm{h}}$ current was as described previously (Kanyshkova et al. 2012). Briefly, $I_{\mathrm{h}}$ current was measured by hyperpolarizing steps of $-10 \mathrm{mV}$ increments from a holding potential of -40 to $-130 \mathrm{mV}$. The fraction of open channels, $p(V)$, yielding the steady-state activation curve of $I_{\mathrm{h}}$, was calculated by normalizing the mean tail current amplitudes in response to an additional step of $1000 \mathrm{~ms}$ to $-100 \mathrm{mV}$ using the following equation:

$p(V)=\left(I-I_{\min }\right) /\left(I_{\max }-I_{\min }\right)$,

where $I_{\max }$ and $I_{\min }$ represent the tail current amplitudes for the voltage step from $-130 \mathrm{mV}$ to $-100 \mathrm{mV}$ and $-40 \mathrm{mV}$ to $-100 \mathrm{mV}$, respectively. $I_{\mathrm{h}}$ activation was fitted by Boltzmann equation of the following form:

$p(V)=1 /\left(1+\exp \left(\left(V-V_{0.5}\right) / k\right)\right)$,

in which $V_{0.5}$ represents the voltage of half-maximal activation and $k$ the slope factor. The amplitude of $I_{\mathrm{h}}$ was calculated by subtracting the instantaneous current amplitude from the steady-state current. The density of $I_{\mathrm{h}}$ was calculated by dividing the $I_{\mathrm{h}}$ current amplitude at $-130 \mathrm{mV}$ by the membrane capacitance obtained during whole-cell recordings. The time course of $I_{\mathrm{h}}$ activation in TC neurons was best approximated by a dual exponential equation as follows:

$I_{\mathrm{h}}(t)=A_{1} \mathrm{e}^{(-t / \tau 1)}+A_{2} \mathrm{e}^{(-t / \tau 2)}$

where $I_{\mathrm{h}}(t)$ is the total amplitude of the current at time $t$, and $A_{1}$ and $A_{2}$ are the respective amplitudes of the components with fast $(\tau 1)$ and slow $(\tau 2)$ time constants.

Membrane outward currents in TC neurons were elicited by holding cells at a potential of $-69 \mathrm{mV}$ followed by hyperpolarization to a conditioning potential of $-129 \mathrm{mV}$ ( $2 \mathrm{~s}$ duration) before stepping to various test potentials ( -99 to $+21 \mathrm{mV} ; 10 \mathrm{mV}$ increment; $200 \mathrm{~ms}$ duration). To allow isolation of $I_{\mathrm{A}}$, we took advantage of its fast inactivating nature and inserted a pre-pulse to $-39 \mathrm{mV}$ (100 ms duration) between the hyperpolarizing condition pulse and the test pulse. Pre-pulse-sensitive currents were analyzed. Inactivation of $I_{\mathrm{A}}$ was investigated by holding neurons at $-69 \mathrm{mV}$ and stepping to different conditioning potentials $(-129$ to $-19 \mathrm{mV}, 2 \mathrm{~s}$ duration, $10 \mathrm{mV}$ increment), before stepping to a constant analyzing test potential of $-9 \mathrm{mV}$ of $100 \mathrm{~ms}$ duration.

The conductance $G$ was estimated from the peak outward current amplitude $I$ (determined within the first $15 \mathrm{~ms}$ of the test pulse) of the pre-pulse-sensitive current (see Fig. 7a) as follows: 


$$
G=I /\left(V-E_{\mathrm{k}}\right)
$$

with $V$ being the voltage of the test pulse and $E_{\mathrm{k}}$ representing the $\mathrm{K}^{+}$equilibrium potential $(-109 \mathrm{mV}$ under the current recording conditions). Activation curves were obtained by fitting a Boltzmann distribution of the following form to the normalized data points:

$G / G_{\max }=1 /\left(1+\exp \left(\left(V-V_{h}\right) / k\right)\right)$,

with $G_{\max }$ being the maximal conductance, $V_{\mathrm{h}}$ the halfmaximal activation and $k$ the slope factor. Inactivation curves were obtained without pre-pulse subtraction and using $I / I_{\max }$ (with $I_{\max }$ being the maximal peak current amplitude). The time course of $I_{\mathrm{A}}$ inactivation in TC neurons was best approximated by a single exponential equation as follows:

$I_{A}(t)=A \mathrm{e}^{(-t / \tau)}$,

where $I_{\mathrm{A}}(t)$ is the amplitude of the current at time $t,{ }_{\mathrm{A}}$ is the maximal current amplitude and $\tau$ the time constant.

\section{Current-clamp recordings}

In this study, the firing pattern and membrane properties of TC neurons such as RMP, input resistance $\left(R_{\text {in }}\right)$, and the $I_{\mathrm{h}^{-}}$ induced voltage sag were characterized by a current-clamp recording protocol consisting of a series of hyperpolarizing and depolarizing current injections ( -200 to $500 \mathrm{pA}$ ) with $20 \mathrm{pA}$ increments, from the resting membrane potential of the cells. The length of each pulse was $1 \mathrm{~s}$. The resting membrane potential of TC neurons was measured during the step with zero current injection.

\section{Preparation of acute brain slices for field potential recordings}

Twelve to 24 week-old male mice were anesthetized with isoflurane. Brains were rapidly removed from the skull and placed in ice-cold slicing solution containing (in $\mathrm{mM}$ ): 234 sucrose, 11 glucose, $24 \mathrm{NaH}_{2} \mathrm{PO}_{4}, 10 \mathrm{MgSO}_{4}$ and 0.5 $\mathrm{CaCl}_{2}$, equilibrated with carbogen. Horizontal slices $(400 \mu \mathrm{m})$ were cut using a microtome (Leica VT $1200 \mathrm{~s}$, Leica, Wetzlar, Germany) and incubated in an oxygenated incubation solution $\left(32{ }^{\circ} \mathrm{C}\right)$ for at least $1 \mathrm{~h}$ prior to recording.

\section{Rhythmic burst activity recordings}

Horizontal brain slices were transferred to an interface chamber and recordings were performed at $32 \pm 1{ }^{\circ} \mathrm{C}$. The superfusion solution consisted of (in $\mathrm{mM}$ ): $\mathrm{NaCl}, 126 ; \mathrm{KCl}$, 2.5; $\mathrm{NaHCO}_{3}, 26 ; \mathrm{NaH}_{2} \mathrm{PO}_{4}, 1.25 ; \mathrm{MgCl}_{2}, 1 ; \mathrm{CaCl}_{2}, 2$; glucose, 10; pH 7.35. Rhythmic burst activity was induced through stimulation of the internal capsule (IC) using a pair of tungsten electrodes (with 50-100 $\mathrm{M} \Omega$ resistance) and network activity was measured in the VB complex using a glass electrode (GC150T-10; Clark Electromedical Instruments, Pangbourne, UK) with a resistance of 0.5-2 M $\Omega$. Burst firing was characterized by at least three high-frequency spikes with an intra-burst frequency of $>100 \mathrm{~Hz}$ and inter-burst interval of not more than $500 \mathrm{~ms}$. Activity was analyzed in a time interval ranging from 50 to $100 \mathrm{~ms}$ up to 2-3 s after stimulation of the IC. In some experiments, ZD7288 was applied via the bath solution. In this case, recordings were performed by first measuring a stable baseline and then recording for $1 \mathrm{~h}$ after ZD7288 application with a stimulation frequency of 1 impulse per minute. All analyses were performed offline using Clampfit 9.2 and Peak v1.0 software.

\section{Electrode implantation and LFP recordings for in vivo electrophysiology}

Three to 5-month old male TRIP8b ${ }^{-/-}$and WT mice were used for the in vivo experiments. Animals were anesthetized with an i.p. injection of $50 \mathrm{mg} / \mathrm{kg}$ pentobarbital supplemented by a subcutaneous injection of Carprofen (Rimadyl; $5 \mathrm{mg} / \mathrm{kg}$ ). The head was fixed in a stereotactic frame (David Kopf Instruments, USA) and holes were drilled into the skull on top of the right hemisphere for the insertion of isolated (except at the tip) stainless steel wire recording electrodes (with the diameter of $0.127 \mathrm{~mm}$; Franco Corradi, Milan, Italy) at the following positions: somatosensory cortex: $A / P=0, M / L=3$, depth $=-1.2$; and ventral posterior medial nucleus (VPM): $A / P=-1.7$, $M / L=-1.5$, depth $=-2.8$. Two epidural silver wires placed on top of the cerebellum served as ground and reference electrodes, respectively. The electrode assembly was fixed to the skull with dental acrylic cement (PulpdentGlassLute, Corporation Watertown, MA; USA). Following surgery, mice were allowed to recover for at least 1 week. Differential LFP signals from cortex and thalamus were recorded continuously for $8 \mathrm{~h}$ starting at 8 am during the light phase of the 12-12 h light-dark cycle. Recordings were performed in Plexiglas registration boxes $\left(30 \times 20 \times 20 \mathrm{~cm}^{3}\right)$. Animals were connected to the recording set up via a cable connected to a swivel allowing the animals to move freely during recording. The LFP signals were amplified with a physiological amplifier (Science Products DPA-2F), filtered by a band-pass filter with cut-off points at 1 (high pass) and 100 (low pass) $\mathrm{Hz}$ and digitalized with a constant sample rate of $2 \mathrm{kHz}$ by a CED recording-system (Cambridge Electronic Design, UK). The behavioral activity of the animals was registered in parallel with the LFP recordings by a Passive Infrared Registration system (PIR, RK2000DPC LuNAR PR 
Ceiling Mount, Rokonet RISCO Group S.A., Belgium) placed on top of the registration box (van Luijtelaar et al. 2012). Following LFP recordings, animals were deeply anesthetized with an overdose of pentobarbital (i.p. injection) and the brain was removed for histological examination of the exact electrode position.

\section{Offline analysis of LFP recordings}

The offline analysis of the recordings was carried out using NeuroExplorer 4 (Nex Technologies, USA) and Spike2 (version7.08, Cambridge Electronic Design Limited, UK) software. Only epochs from the first $2 \mathrm{~h}$ of the light period were selected for analysis; these hours represent the periods with the largest amount of specifically deep non-REM sleep (Huber et al. 2000). LFP data from cortex and thalamus from 20 epochs of $10 \mathrm{~s}$ duration of active-wakefulness and deep non-REM sleep of each animal were selected based on the EEG and PIR activity according to commonly used criteria (van Luijtelaar et al. 2012). For non-REM sleep, criteria included high-amplitude cortical EEG together with slow $(1-5 \mathrm{~Hz})$ waves in a motionless animal (as established by the PIR signal). For active-wakefulness criteria included behavioral activity (high and variable PIR signal accompanied by low-amplitude cortical EEG with theta and or beta) for the WT mice; in TRIP8b ${ }^{-1-}$ the PIR signal was only used since a dissociation between EEG and behavior was noticed (see results and discussion) and a high-amplitude and changing PIR signal was the only criterion used to establish active-wakefulness. The power spectral density (PSD) of all these epochs of non-REM sleep and active-wakefulness were calculated and averaged for each individual animal, the power density of the peak frequency of the conventional frequency bands $(\delta 1-4 \mathrm{~Hz}$, $\theta 4.5-8 \mathrm{~Hz}, \alpha 8.5-11$, and $\beta$ 11.5-30) was used for statistical analysis. To control for individual differences in EEG amplitude and PSD's, relative values (Z-transformed) and percentages were analyzed.

\section{Histological verification of electrode positions}

Correct placement of the electrodes was examined at the end of each experiment. Animals were deeply anaesthetized with isoflurane and a direct current of $9 \mathrm{~V}, 25 \mu \mathrm{A}$, with $10 \mathrm{~s}$ duration was passed through each electrode. Then animals were perfused with $4 \%$ phosphate-buffered paraformaldehyde (PFA). Brains were removed and postfixed overnight in 4\% PFA and later in 30\% sucrose for $48-72 \mathrm{~h}$. Free-floating coronal sections $(40 \mu \mathrm{m})$ were cut with a microtome and stained with Cresyl-violet. Only animals with confirmed electrode positions were included for analysis.

\section{Drugs}

Modulation of $I_{\mathrm{h}}$ by cyclic nucleotides was measured using different concentrations of 8-bromo adenosine- $3^{\prime}, 5^{\prime}$-cyclic monophosphate (8-Br-cAMP) sodium salt (Sigma-Aldrich, Germany), applied intracellularly through the recording pipette. The effects of 2-Chloro- $N$ 6-cyclopentyladenosine (CCPA; Tocris Bioscience, UK), an adenosine A1 receptor agonist, was assessed by bath application of $100 \mu \mathrm{M}$ of the compound. For experiments performed in the presence of SQ22536 (Sigma-Aldrich, Germany), an adenylyl cyclase inhibitor, slices were incubated for at least $1.5 \mathrm{~h}$ in $200 \mu \mathrm{M}$ of the compound. In some experiments, $I_{\mathrm{h}}$ was abolished using different concentrations of ZD7288 (Tocris Bioscience, Bristol, United Kingdom) which was applied extracellularly. To reduce the excitability of cortical pyramidal neurons during voltage-clamp recordings, $0.5 \mu \mathrm{M}$ of TTX (Merck, Darmstadt, Germany) was added to the external solution. For isolation of $I_{\mathrm{A}}$, we used $1 \mathrm{mM}$ EGTA and 10 mM TEA-Cl (Sigma-Aldrich, Germany).

\section{Quantitative PCR}

Real-time PCR was performed using the Taq-Man universal PCR master mix (Thermo Fisher Scientific, Massachusetts, USA) and the ABI Prism 7000 sequence detection system (Thermo Fisher Scientific, USA) (Budde et al. 2005; Kanyshkova et al. 2014). The PCR program was as follows: $2 \mathrm{~min}$ at $50{ }^{\circ} \mathrm{C}, 10 \mathrm{~min}$ at $95{ }^{\circ} \mathrm{C}, 50$ cycles of $15 \mathrm{~s}$ at $95^{\circ} \mathrm{C}$ and $1 \mathrm{~min}$ at $60^{\circ} \mathrm{C}$. Results were analyzed with ABI Prism 7000 SDS software. Quantification was done using the comparative $C_{\mathrm{T}}$ or $\Delta \Delta C_{\mathrm{T}}$ method as described in the ABI User Bulletin\#2 (Thermo Fisher Scientific). Hybridization primer/probe assays for real-time PCR detection of hcn 1 , $h c n 2, h c n 3$, and hcn 4 were purchased from Thermo Fisher Scientific.

\section{Western blotting}

Brain tissues were homogenized in ice-cold lysis buffer containing $1 \%$ Triton, $150 \mathrm{mM}$ of $\mathrm{NaCl}, 50 \mathrm{mM}$ of TRIS base, $\mathrm{pH}$ 7.5, with protease inhibitors (Complete Ultra tablets, Mini, EDTA-Free, Easypack; Sigma-Aldrich, Germany) using a glass Teflon homogenizer followed by three times vortex mixing with $10 \mathrm{~min}$ intervals. The homogenate was centrifuged for $15 \mathrm{~min}, 14,000 \times g\left(4{ }^{\circ} \mathrm{C}\right)$, and the supernatant was used for Western blot analysis. Samples $(10 \mu \mathrm{g}$ protein) were loaded and separated by a $7.5 \%$ sodium dodecyl sulfate polyacrylamide gel (SDSPAGE). Proteins were transferred onto nitrocellulose membrane at $20 \mathrm{~V}$ overnight. Membranes were incubated in a blocking buffer containing 5\% non-fat milk in $1 \times$ TBS 
buffer $(50 \mathrm{mM}$ of Tris- $\mathrm{HCl}, 150 \mathrm{mM}$ of $\mathrm{NaCl}$ ) containing $0.1 \%(\mathrm{w} / \mathrm{v})$ Tween 20 (TBST), $\mathrm{pH} 7.4$ for $3 \mathrm{~h}$ at room temperature on a shaker and then incubated for $48 \mathrm{~h}$ at $4{ }^{\circ} \mathrm{C}$ with primary antibodies [polyclonal rabbit (rb)-antiHCN1 (1:100); rb-anti-HCN2 (1:100); and rb-anti-HCN4, $(1: 100)]$. Antibodies were purchased from Alomone Labs (Jerusalem, Israel). Membranes were washed three times for $10 \mathrm{~min}$ in washing buffer containing $1 \%$ (w/v) non-fat milk in TBS, and incubated with horseradish peroxidaseconjugated goat anti-rabbit secondary antibodies (polyclonal goat (gt) anti-rb HRP 1:1500; Dako, Denmark) in $1 \%(\mathrm{w} / \mathrm{v})$ non-fat milk in TBST for $1 \mathrm{~h}$ at room temperature and washed (three times for $10 \mathrm{~min}$ ) in TBST buffer thereafter. Bound antibodies were visualized using an enhanced chemiluminescent detection system. Quantification of HCN channel expression was by densitometric analysis of corresponding protein bands using ImageJ software. HCN channel signals were normalized to $\beta$ tubulin (anti- $\beta$-tubulin, 1:500, Abcam, UK) that was stained as an internal control and loading standard.

\section{Immunofluorescence}

Twenty-five to thirty-day-old TRIP8b ${ }^{-1-}$ and C57BL/6J (WT) mice were transcardially perfused with 4\% PFA. Brains were removed and post-fixed for $2 \mathrm{~h}$ in $4 \%$ PFA and later in $30 \%$ sucrose for $48-72 \mathrm{~h}$. Free-floating coronal sections $(40 \mu \mathrm{m})$ were cut and slices were collected in phosphate-buffered saline (PBS). Sections were washed three times for $10 \mathrm{~min}$ in PBS, preincubated for $20 \mathrm{~min}$ in PBS containing $0.3 \%(\mathrm{w} / \mathrm{v})$ Triton-X100 (PBST). Slices were then incubated for $2 \mathrm{~h}$ in $6 \%(\mathrm{v} / \mathrm{v})$ normal goat serum in PBST and incubated with primary antibodies: polyclonal rb-anti-HCN1, rb-anti-HCN2, rb-anti-HCN4 (1:200; Alomone Labs, Israel) and mouse (ms)-anti-TRIP8b (1:50; NeuroMab, USA) for $48 \mathrm{~h}$ at $4{ }^{\circ} \mathrm{C}$. After incubation with the primary antibody, slices were washed three times for $10 \mathrm{~min}$ in PBS and thereafter transferred to the secondary antibody solution (Alexa Fluor 568 gt-anti-rb-IgG, 1:1000 and Alexa Fluor 488 gt-anti-ms-IgG, 1:1000) for 1 hour, washed three times for $10 \mathrm{~min}$ and mounted with a mounting medium (VECTASHIELD with DAPI, Vector Laboratories Inc., Burlingame, CA, USA) for confocal microscopy.

\section{Quantification of cAMP levels in tissue samples}

Tissue from WT and TRIP8b $\mathrm{b}^{-1-}$ mice was dissected from sacrificed animals in ice-cold buffer containing (in $\mathrm{mM}$ ): sucrose, 200; PIPES, 20; $\mathrm{KCl}, 2.5 ; \mathrm{NaH}_{2} \mathrm{PO}_{4}, 1.25$; $\mathrm{MgSO}_{4}, 10 ; \mathrm{CaCl}_{2}, 0.5$; dextrose, 10; pH 7.35 (with $\mathrm{NaOH}$ ) and further incubated in an oxygenated salt solution (in mM: $\mathrm{NaCl}, 125 ; \mathrm{KCl}, 2.5 ; \mathrm{NaH}_{2} \mathrm{PO}_{4}, 1.25 ;$ HEPES, 30; glucose, $10 ; \mathrm{CaCl}_{2}, 2 ; \mathrm{MgCl}_{2}, 1$; IBMX, 0.05,pH 7.3) for $2 \mathrm{~h}$. Samples were snap frozen in liquid nitrogen and stored at $-80^{\circ} \mathrm{C}$ before further use. All samples were thawed on ice and vortexed for $1 \mathrm{~min}$ at room temperature. To get rid of any non-solubilized material, samples were centrifuged at $1000 \times g$ for $10 \mathrm{~min}$ at $4{ }^{\circ} \mathrm{C}$. The supernatant was transferred to a new Eppendorf cup and kept on ice. The amount of cAMP was determined with the cAMP-Screen assay kit (Applied Biosystems/ThermoFisher Scientific, Dreieich, Germany) following the supplier's protocol. Determinations were performed in triplicates using $60 \mu \mathrm{l}$ of tissue homogenate per assay. The protein content of each sample was determined by the Bradford Protein Assay (Bio-Rad, Munich, Germany). Values of cAMP were given per mg total protein. Calculations were done with GraphPadPrism 5.04 software (GraphPad, San Diego, CA, USA).

\section{Mathematical modeling}

Simulations were conducted within the NEURON simulation environment (Hines and Carnevale 2001; Meuth et al. 2005 ) based on a modified version of an intrathalamic and a thalamocortical network model consisting of four and eight cells, respectively (Destexhe et al. 1996, 1998). The four-cell model comprised two spontaneously pacemaking TC neurons and two reticular thalamic (nRT) neurons interacting via $\mathrm{GABA}_{\mathrm{A}}, \mathrm{GABA}_{\mathrm{A}+\mathrm{B}}$ and AMPA synapses (see Fig. 9a). While nRT neuron parameters were not changed, the $I_{\mathrm{h}}$ module of both TC neurons was modified by introducing activation kinetics and conductance obtained from our voltage-clamp recordings in nine WT and ten TRIP8b ${ }^{-/-}$cells. Four different cell types were used for the eight-cell model (Destexhe et al. 1998), namely two cortical pyramidal neurons (PY), two cortical interneurons (IN), two TC neurons and two reticular thalamic neurons. The connectivity of the four different cell types is shown in Fig. 9d. As in the four-cell model, $I_{\mathrm{h}}$ parameters obtained from voltage-clamp recordings in TC and PY neurons were used in eight-cell simulation of network activity.

\section{Statistics}

All results are presented as mean \pm SEM. Comparison of $I_{\mathrm{h}}$ characteristics between TRIP8b ${ }^{-1-}$ and WT cells in different regions of the brain was performed by separate Student's $t$ tests. In case of multiple comparisons, such as in cAMP dose-response study or CCPA and SQ22536 studies either ANOVA or repeated-measures ANOVA were used. For in vivo experiments, comparison of the PSD between different states of vigilance, frequency bands and strains was done with Repeated-Measures ANOVA, in which the state of vigilance (wakefulness, deep non-REM sleep) and frequency band were set as within subject 
factors and groups (WT and TRIP8b ${ }^{-1-}$ ) as between-subject factor. For comparisons within the state of vigilance, groups and frequency band served as independent variables (between and within subjects factors, respectively) for the two-way repeated-measures ANOVA. Student's $t$ tests were used as Post Hoc tests, if necessary. Separate analyses were done for the cortical and thalamic PSD. Data analysis and figure plotting were performed by IBM SPSS Statistic software (version 22, USA), Corel DRAW X4 and OriginPro (version 8G, OriginLab, Friedrichsdorf, Germany) software.

\section{Results}

\section{TRIP8b $^{-1-}$ mice show slower cortical and thalamic oscillations during active-wakefulness}

The two firing patterns of thalamocortical neurons, namely tonic and burst firing, are generated as a result of a complex interplay between different ionic conductances including $I_{\mathrm{h}}, I_{\mathrm{T}}$ and conventional $I_{\mathrm{Na}}$. Especially, bursting is involved in the generation of thalamocortical rhythms such as delta and spindle oscillations which are found in EEG recordings during non-rapid eye movement (non-REM) sleep and anesthesia (Steriade et al. 1993; Timofeev and Bazhenov 2005). Therefore, dysregulation in any of these ionic conductances is expected to induce changes in thalamocortical oscillations. Given the importance of TRIP8b in regulation of $I_{\mathrm{h}}$ in both TC and cortical pyramidal neurons (Heuermann et al. 2016), we assessed the effects of TRIP8b deletion on thalamocortical network oscillations by performing LFP recordings from thalamus and cortex of freely moving mice (Fig. 1a). The LFP during non-REM sleep seemed normal in TRIP8b ${ }^{-1-}$ mice (see Fig. 2f). In contrast, the signal during active-wakefulness in TRIP8b ${ }^{-/-}$ mice, as was unambiguously determined with the aid of the passive infrared registration (PIR) signal (van Luijtelaar et al. 2012), differed from that in WT (see Figs. 1a and 2f) with the cortical and thalamic EEG mimicking non-REM sleep. Comparison of the power spectral density (PSD) of the different frequency bands between TRIP8b ${ }^{-1-}$ and WT mice during episodes of active-wakefulness demonstrated more (ANOVA's followed by Student's $t$ tests, $p$ 's $<0.05$, $n=7 / 7)$ delta power in cortical and thalamic LFPs and less ( $p$ 's $<0.05, n=7 / 7$, see Fig. 1c) energy in the cortical and thalamic LFP's of theta, alpha and beta bands in TRIP8b $^{-1-}$ compared to WT mice. The percentage of delta power (Fig. 1d, $p$ 's $<0.05$ for both cortex and thalamus) was also higher in TRIP8b ${ }^{-1-}$ than in WT mice. In contrast, no significant differences between the two groups were observed in the power values of LFPs during nonREM sleep (Fig. 2a, b).
It is known that during non-REM sleep delta oscillations are the predominant oscillatory activities of the brain with a higher PSD than during wakefulness, and that during activewakefulness these slow oscillations are replaced by faster oscillations (theta, beta and gamma) with peak amplitudes in the theta frequency range. Therefore, in an intact thalamocortical system, the EEG desynchronizes during (active) wakefulness. This implies that a predominantly high-amplitude low-frequency EEG during non-REM sleep is replaced by low-amplitude high frequencies characterizing wakefulness. Although both TRIP8b ${ }^{-1-}$ and WT mice had a higher delta power density during non-REM sleep compared to active-wakefulness (Fig. $2 \mathrm{a}$ and $\mathrm{b}$ ), TRIP8 $\mathrm{b}^{-1-}$ mice showed significantly less-pronounced changes in thalamic and cortical delta frequency oscillations compared to WT mice, as was revealed by a smaller difference in scores between deep non-REM sleep and active-wakefulness (Fig. 2c-f) in TRIP8b ${ }^{-1-}$ mice. Therefore, the deletion of TRIP8b suppressed the typical desynchronization response of the brain which normally happens at the transition from non-REM sleep to wakefulness.

The occurrence of absence epileptic activity in TRIP8bdeficient mice has been reported before (Heuermann et al. 2016). Here, we did not find clear patterns of trains of highamplitude sharp spikes and slow waves characterizing absence seizures (spike-and-wave discharges, SWDs) in established rodent absence epilepsy models (van Luijtelaar and Sitnikova 2006; Arain et al. 2015). However, some isolated short $(<1 \mathrm{~s})$ irregular spindle complexes were found in 2 out of 9 animals with the incidence of total of 2 to 3 spike-like activities in $8 \mathrm{~h}$ recording period.

In summary, the EEG analyses revealed that delta oscillations are prominent in waking TRIP8b-deficient mice and that the desynchronization response is more subtle than in WT mice. This identifies TRIP8b as a molecule which contributes to acceleration and desynchronization of thalamocortical oscillations.

\section{TRIP8b does not change hcn channel gene expression pattern but regulates $\mathrm{HCN}$ protein expression in the thalamocortical system}

Since TRIP8b is known to regulate the surface expression of HCN channels in different brain regions (Santoro et al. 2004, 2009), we assessed whether changes in thalamocortical oscillations are associated with altered hcn channel gene transcription and translation. We first quantified the mRNA levels of $h c n 1-4$ by qPCR in samples from cortex and thalamus dissected from WT and TRIP8b ${ }^{-1-}$ mice. No difference in gene expression was detected for any of the $h c n$ genes in the somatosensory cortex (SSC), the posterior thalamic nucleus (PO), the ventral-basal complex (VB), the dorsal part of the lateral geniculate nucleus (dLGN) and 
a

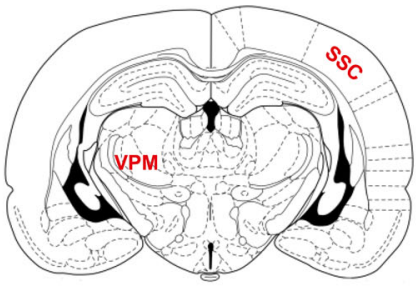

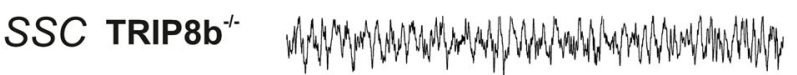

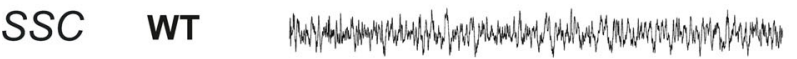

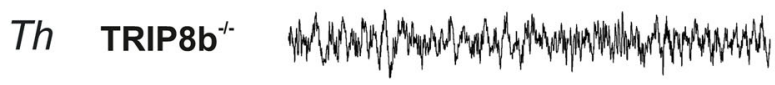

Th

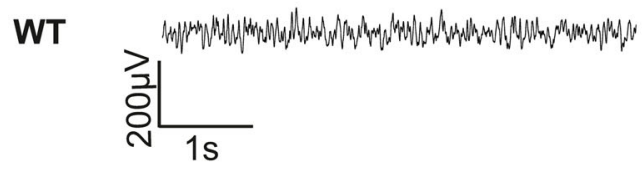

C

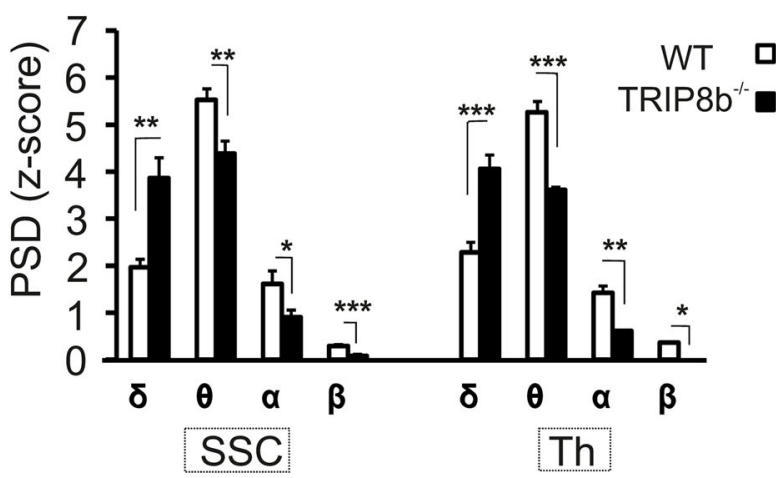

Fig. 1 Modulation of thalamocortical oscillatory activities during active-wakefulness by TRIP8b. a Sample LFP recordings ( $5 \mathrm{~s}$ epochs) from somatosensory cortex (SSC) and ventral-posterior-medial nucleus (VPM) of the thalamus (Th) of TRIP8b ${ }^{-1-}$ and WT animals during active-wakefulness, indicating an increase in the power of delta oscillations in TRIP8b $\mathrm{b}^{-1-}$ mice compared to WT animals. b Example of time-frequency analysis of cortical and thalamic oscillatory activities (each plot shows an average of 20 epochs of $10 \mathrm{~s}$ duration) for a single animal during active-wakefulness for WT and

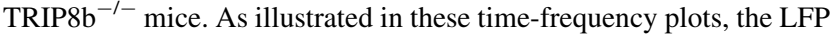
of WT during active-wakefulness in SSC and Th mainly contains

the centromedial thalamic nucleus (CM) (Supplemental Figure 1a). In contrast, Western blot analysis demonstrated a significant reduction in the protein level of three $\mathrm{HCN}$ channel subunits (HCN1, HCN2, HCN4) in both the thalamus and cortex of TRIP8b ${ }^{-1-}$ mice compared to WT animals (Student's $t$ tests, $n=4 / 4$ mice, $p$ 's $<0.05$, see Fig. 3a-d). The reduction in the protein level of different HCN channel subunits was accompanied by a reduction in the surface expression of the proteins, as illustrated by immunostaining with specific antibodies directed against HCN1, HCN2, HCN4 and TRIP8b on tissue sections encompassing regions of the thalamus, here PO, VB,
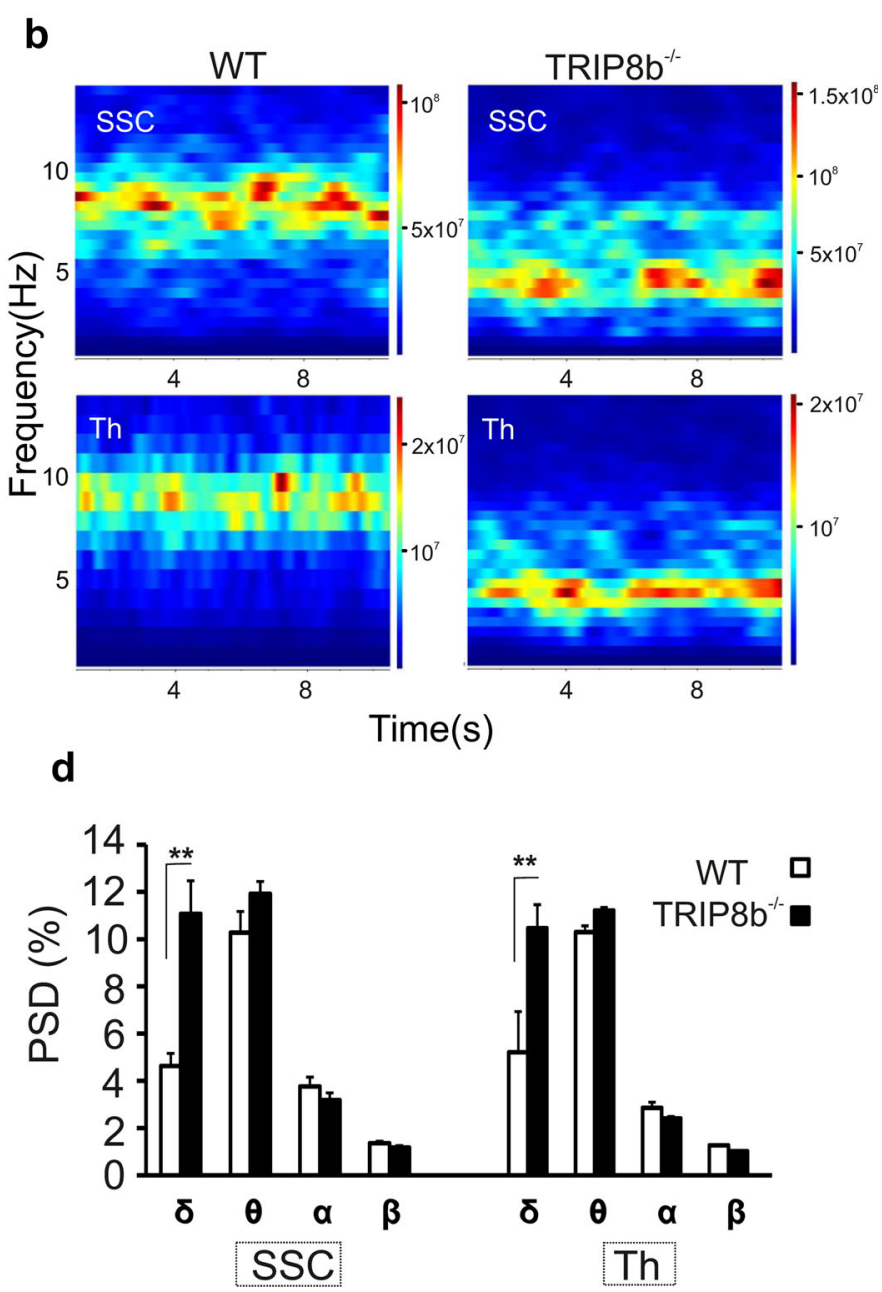

frequencies in the range of $6-11 \mathrm{~Hz}$ with a peak power around $7-10 \mathrm{~Hz}$. However, in TRIP8b $\mathrm{b}^{-1-}$, the dominant frequencies during wakefulness range between 2 and $7 \mathrm{~Hz}$ in SSC and Th with a peak power at 3-4 Hz. c Bar graphs comparing the normalized peak PSD (z-score) of four frequency bands $(\delta-\beta)$ between WT (white bars) and

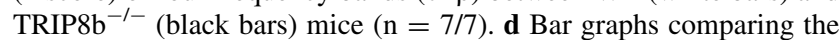
percentage of PSD (PSD \%) of four frequency bands $(\delta-\beta)$ between WT (white bars) and TRIP8b ${ }^{-l-}$ (black bars) mice. Mixed repeatedmeasures ANOVA followed by Student's $t$ tests. ${ }^{*}, * *, * * *$ indicate $p<0.05, p<0.01, p<0.001$, respectively

dLGN, CM and cortex of TRIP8b ${ }^{-1-}$ and WT mice. As shown in Fig. 3e-h for WT animals, TRIP8b was detected in somata and dendrites of neurons in both the thalamus and layer $\mathrm{V}$ of the SSC, with overlapping expression profiles for HCN1 (in cortex), HCN2 (in thalamus and cortex) and HCN4 (in thalamus). Less dendritic expression of TRIP8b was detected in pyramidal neurons of layer VI (see Supplemental Figure 1b). Here, TRIP8b was mainly expressed in somata and strongly overlapped with HCN1 and HCN2 subunit expression. In TRIP8b ${ }^{-1-}$, mice a pronounced reduction in the general expression of $\mathrm{HCN}$ subunits in both cortex and different thalamic regions was 

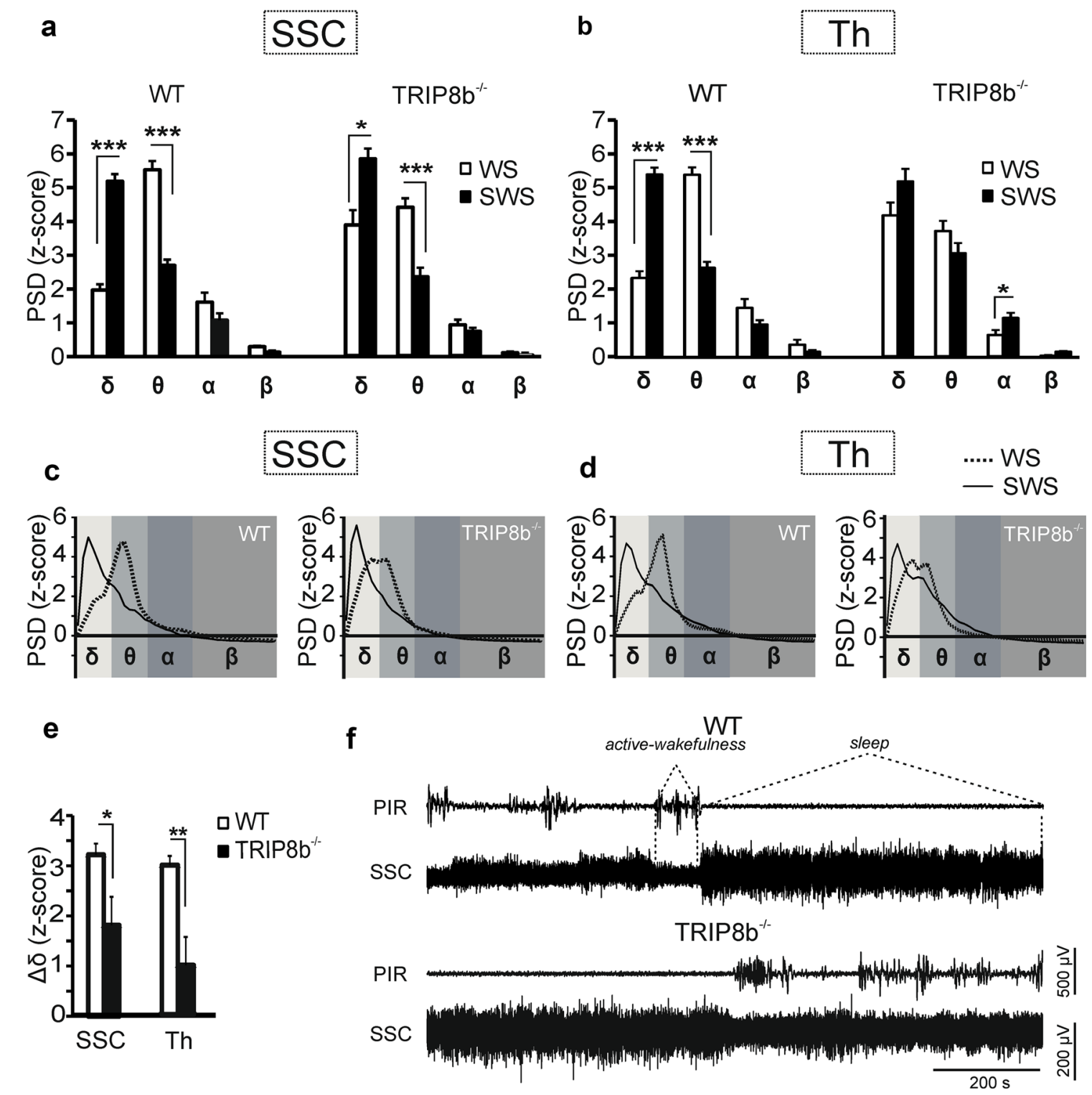

Fig. 2 Modulation of cortical and thalamic slow-frequency oscillations by TRIP8b during episodes of slow-wave sleep and activewakefulness. a and b Bar graphs comparing the normalized peak frequency PSD (z-score) of four frequency bands $(\delta-\beta)$ in somatosensory cortex (SSC) and VPM (Th) of WT and TRIP8b ${ }^{-1-}$ mice between episodes of active-wakefulness (WS) and slow-wave sleep (SWS). (mixed repeated measures ANOVAs followed by Student's $t$ tests, $n=7 / 7, *$, **, *** indicate $p<0.05, p<0.01, p<0.001$, respectively). c and d Representative spectrograms indicating the difference between the PSD during WS and SWS. e Bar graph comparing the changes in delta frequency oscillations $(\Delta \delta)$ between the deep non-REM sleep (SWS) and active-wakefulness in WT and

observed (Fig. 3e-h and Supplemental Figs 1-4). In line with the results of previous studies (Heuermann et al. 2016), our immunohistochemistry data revealed that GABAergic neurons of the nRT did not express TRIP8b (Supplemental Figure 5a), which argues against significant changes of $I_{\mathrm{h}}$ in these neurons in TRIP8b ${ }^{-1-}$. In addition, immunostaining of the cortical and thalamic local circuit
TRIP8b $^{-1-}$ mice. As illustrated, TRIP8 $\mathrm{b}^{-1-}$ mice $(n=7)$ show less (Student's $t$ tests, $p<0.05$ for SSC and $p<0.01$ for thalamus) changes in $\Delta \delta$ compared to WT $(n=7)$ mice. f Sample LFP recordings from the SSC of WT (upper panel) and TRIP8b ${ }^{-1-}$ (lower panel) mice, showing the EEG signal during non-REM sleep and active-wakefulness in combination with the signal recorded from infrared movement detector (PIR). Note the smaller difference in the amplitude of the LFP between deep non-REM sleep and activewakefulness in TRIP8b $\mathrm{b}^{-1-}$ compared to WT mice. Dashed lines indicate episodes of sleep and active-wakefulness detected with the aid of both PIR and LFP signal

interneurons of GAD67/GFP knock-in mice with antibody against TRIP8b did not show any co-expression with TRIP8b in these neurons (see Supplemental Figure 5b-c). In these knock-in mice, the GABAergic neurons are labeled by expression of a green fluorescent protein (GFP) under control of the glutamate decarboxylase (GAD67/ Gad1) promoter. 


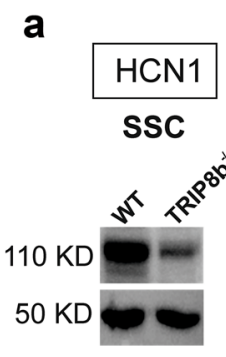

b

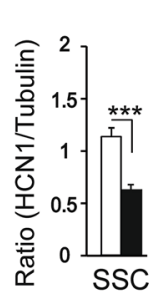

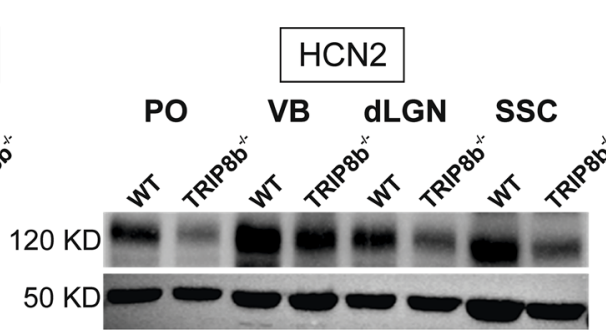

C

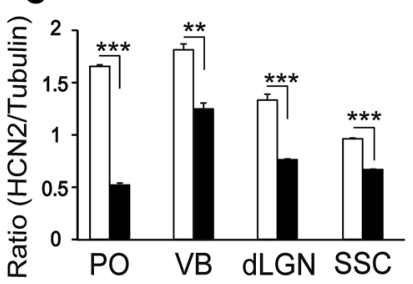

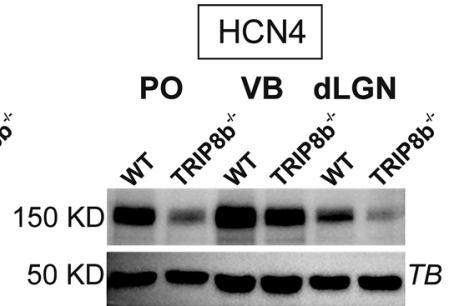

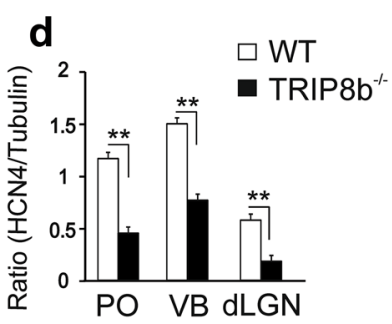

e

DAPI

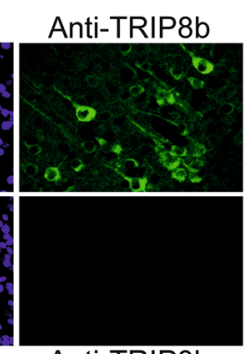

Anti-HCN1

Merge
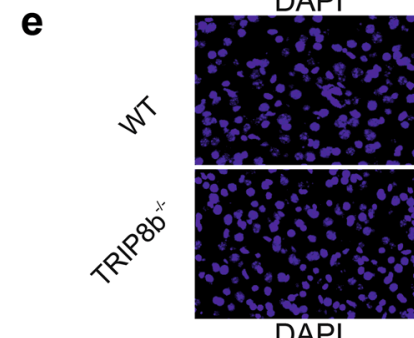

f
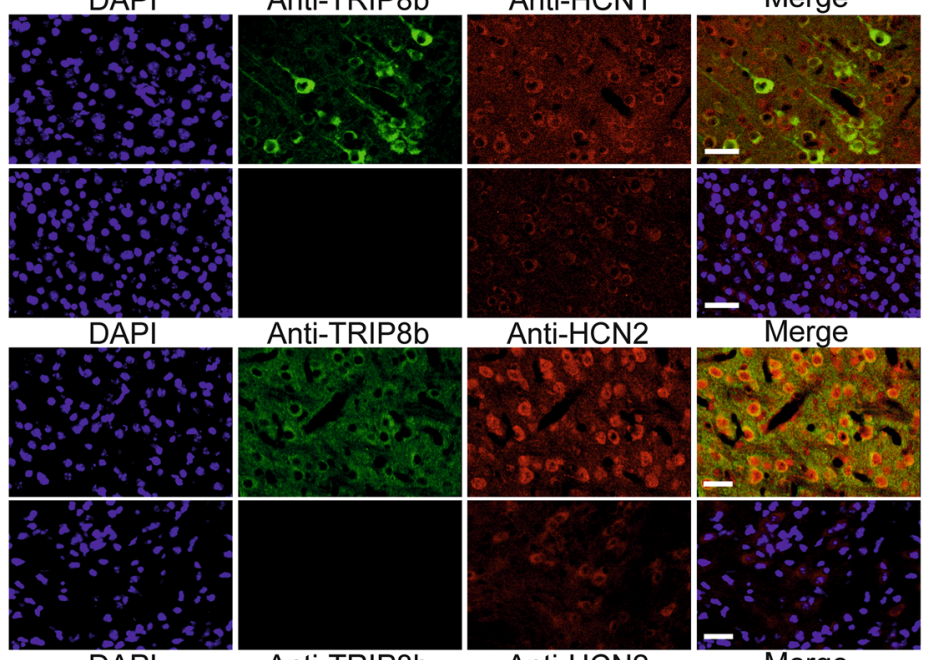

g
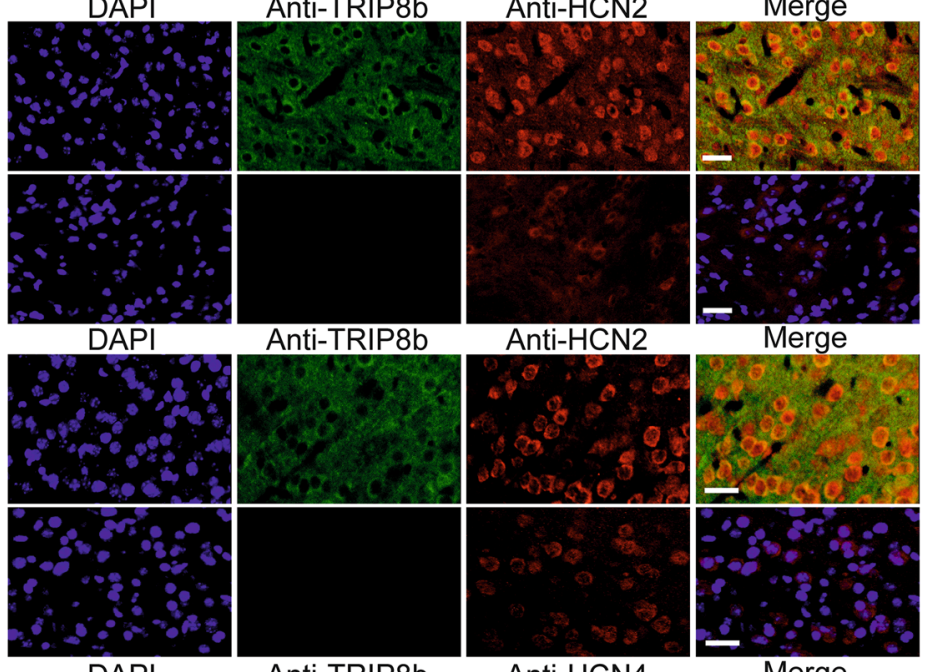

h
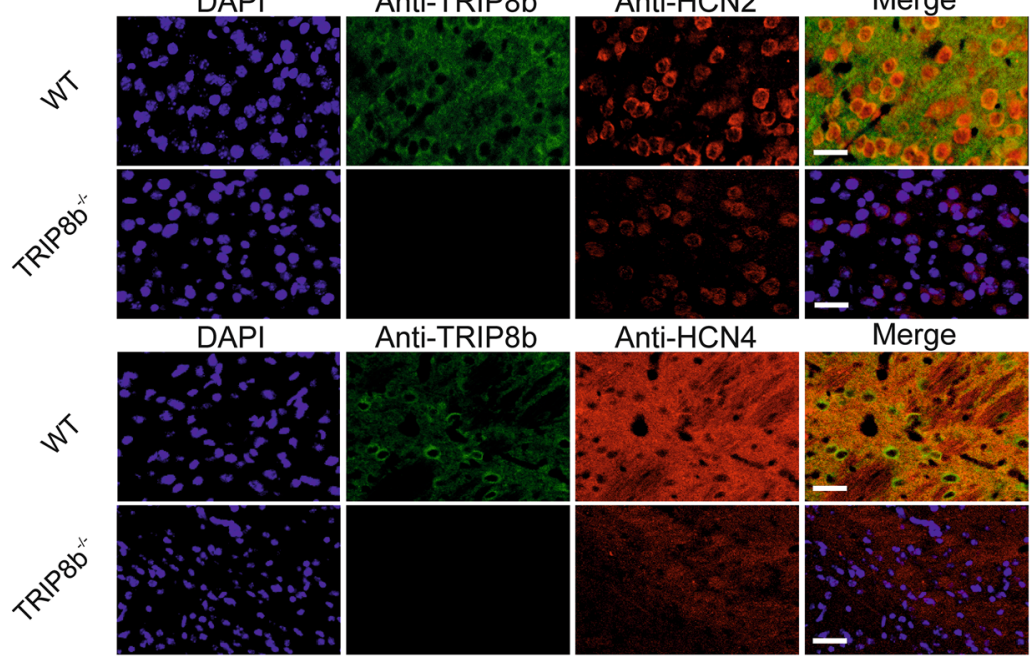

Anti-HCN4

Merge

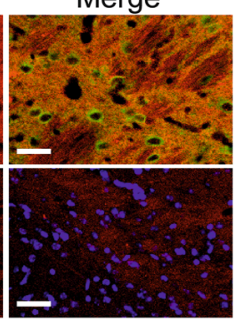


4Fig. 3 Modulation of HCN channel expression in thalamus and somatosensory cortex by TRIP8b. a For Western blotting, a total amount of $10 \mu \mathrm{g}$ of protein was separated by SDS-PAGE and transferred onto nitrocellulose membrane. Blots were incubated with specific antibodies directed against HCN1 (rb- $\alpha-\mathrm{HCN} 1 ; 1$ : 100), HCN2 (rb- $\alpha-\mathrm{HCN} 2 ; 1: 100)$, HCN4 (rb- $\alpha$-HCN4; $1: 100)$, and $\beta-$ tubulin (anti- $\beta$-tubulin; 1 : 500; TB). Bound primary antibodies were detected by gt-anti-rb HRP-coupled secondary antibodies and visualized by ECL. The size of the labeled bands is given in kilo Daltons (KD). In comparison to WT samples, the amount of HCN channel subunits (HCN1, 2 and 4) in different regions of thalamus and cortex of TRIP8 $\mathrm{b}^{-1-}$ mice was reduced. SSC, PO, VB and dLGN represent somatosensory cortex, posterior thalamic nucleus, ventral-basal complex and dorsal part of the lateral geniculate nucleus, respectively. $\mathbf{b}, \mathbf{c}$ and $\mathbf{d}$ Representative graphs displaying the ratio between HCN1, HCN2, HCN4 and $\beta$-tubulin (from left to right) between WT and TRIP $8 \mathrm{~b}^{-1-}$ mice (Student's $t$ tests, $n=4 / 4$, **, *** indicate $p<0.01$ and $p<0.001)$. e, $\mathbf{f}, \mathbf{g}, \mathbf{h}$ Immunohistochemical staining of HCN channel subunits in VB complex of the thalamus and cortex of WT and TRIP8b $\mathrm{b}^{-1-}$ mice. DAPI staining was performed to identify the nuclei and is depicted in blue (first column); staining of TRIP8b (ms-anti-TRIP8b, 1:50) is depicted in green (second column); staining of $\mathrm{HCN}$ channel isoforms is depicted in red (rb-anti-HCN1, - HCN2 and $-\mathrm{HCN} 4,1: 200$, third column), merged images are depicted in the fourth column. e Specific labeling of HCN1 and TRIP8b in pyramidal neurons of layer $\mathrm{V}$ of the somatosensory cortex in WT and TRIP8b $^{-/-}$mice. Scale bar indicates $25 \mu \mathrm{m}$. f Specific labeling of HCN2 and TRIP8b in VB complex of WT (upper panel) and

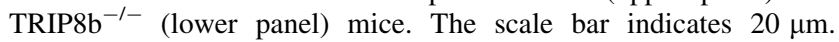
g Specific labeling of HCN2 and TRIP8b in somatosensory cortex of WT (upper panel) and TRIP8b ${ }^{-1-}$ mice. Scale bar indicates $25 \mu \mathrm{m}$. h Specific labeling of HCN4 and TRIP8b in VB complex of WT and TRIP8b $^{-1-}$ mice. Scale bar indicates $25 \mu \mathrm{m}$

These results indicate that the regulatory effect of TRIP8b on HCN channels is not at the transcriptional level but rather via its role in controlling surface expression of the channels.

\section{Properties of $I_{h}$ in cortical pyramidal neurons in the absence of TRIP8b}

We used electrophysiological experiments to assess how reduced $\mathrm{HCN}$ channel expression influences $I_{\mathrm{h}}$ properties. Recordings of $I_{\mathrm{h}}$ currents were performed in pyramidal neurons of layers V and VI of the SSC. Measurements were carried out under voltage-clamp conditions. As shown in Supplemental Figure 5a and b, lack of TRIP8b resulted in a significant reduction in $I_{\mathrm{h}}$ current density in both cortical layers (layer V WT, $2.7 \pm 0.4 \mathrm{pA} / \mathrm{pF}$ vs. layer V TRIP8b ${ }^{-/-}$ $1.2 \pm 0.2 \mathrm{pA} / \mathrm{pF}, n=8 / 9$ cells, $p<0.001$ and layer VI WT, $1.4 \pm 0.3 \mathrm{pA} / \mathrm{pF}$ vs. layer VI TRIP8b ${ }^{-1-}, 0.5 \pm 0.1 \mathrm{pA} / \mathrm{pF}$, $n=6 / 6$ cells, $p<0.05$, see Supplemental Figure $6 \mathrm{~b}$ ). In addition, analyses of steady-state activation curves in layer $\mathrm{V}$ pyramidal cells showed a significant negative shift in the voltage-dependent activation of $I_{\mathrm{h}}$ in TRIP8b ${ }^{-1-}$ mice compared to WT animals (layer V WT, $V_{0.5}=-90.6 \pm 0.9 \mathrm{mV}$ vs. layer V TRIP8b ${ }^{-1-}, V_{0.5}=-94.0 \pm 1.0 \mathrm{mV}, n=8 / 9$ cells, $p<0.05$, Supplemental Figure $6 \mathrm{c}$ ). Due to the rather small amplitude of $I_{\mathrm{h}}$ in layer VI neurons, a reliable calculation of $V_{0.5}$ was not possible for these neurons. Therefore, I/V curves were generated by plotting mean $I_{\mathrm{h}}$ current density against the different hyperpolarizing step potentials (Supplemental Figure 6d). Data revealed a significant reduction in $I_{\mathrm{h}}$ current density in layer VI neurons from TRIP8b ${ }^{-1-}$ compared to WT animals (Mixed Repeated Measure ANOVA, $p<0.05, n=6 / 6)$. When current kinetics were analyzed, no significant differences in the fast component of $I_{\mathrm{h}}$ were found between TRIP8 $\mathrm{b}^{-1-}$ and WT neurons, suggesting that the time-dependent activation of $\mathrm{HCN}$ channels remained unaltered in TRIP8b ${ }^{-1-}$ mice. Only three out of nine recorded neurons from TRIP8b $^{-1-}$ mice showed two-exponential activation time profiles. Therefore, a reliable comparison for $T_{2}$ between the two groups was not possible. Reduction of $I_{\mathrm{h}}$ current density in layer $\mathrm{V}$ neurons also resulted in a significant negative shift in RMP (WT, RMP $=-68.4 \pm 2.7 \mathrm{mV}$, $n=8$ cells and $\mathrm{TRIP}^{-1-} \mathrm{b}^{-1} \mathrm{RMP}=-76.9 \pm 1.5 \mathrm{mV}$, $n=9$ cells, $p<0.05$ ) with no effects on RMP in layer VI (data not shown).

These data indicate that loss of TRIP8b reduces $I_{\mathrm{h}}$ current density and influences $\mathrm{HCN}$ channel steady-state activation properties in cortical neurons.

\section{Properties of $I_{h}$ in different regions of the thalamus in the absence of TRIP8b}

To assess the role of TRIP8b in the regulation of $\mathrm{HCN}$ channels in functionally different regions of the thalamus, $I_{\mathrm{h}}$ currents were examined in various nuclei of the thalamus, including PO, dLGN, CM, and VB complex. In the absence of TRIP8b, all TC neurons showed strongly reduced $I_{\mathrm{h}}$ amplitude and significant reduction in current density calculated at the hyperpolarization step to $-130 \mathrm{mV}$ (WT VB, $11.75 \pm 0.7 \mathrm{pA} / \mathrm{pF}, n=9$ cells, and $\mathrm{TRIP}^{-1-} \mathrm{VB}$, $2.3 \pm 0.2 \mathrm{pA} / \mathrm{pF}, n=10$ cells, $p<0.001 ;$ WT PO, $8.5 \pm 1.2 \mathrm{pA} / \mathrm{pF}, n=9$ cells, and TRIP8b ${ }^{-/-} \mathrm{PO}, 2.7 \pm 0.2$ $\mathrm{pA} / \mathrm{pF}, n=8$ cells, $p<0.01$; WT CM, $4.5 \pm 0.7 \mathrm{pA} / \mathrm{pF}$, $n=8$ cells, and TRIP8b ${ }^{-1}$ CM, $1.5 \pm 0.193 \mathrm{pA} / \mathrm{pF}, n=6$ cells, $p<0.01$; WT dLGN, 7.1 $\pm 1.3, n=9$ cells and TRIP8b $^{-1-}$ dLGN, $\quad 2.3 \pm 0.2 \mathrm{pA} / \mathrm{pF}, \quad n=8$ cells, $p<0.001$; Supplemental Figure 7a and b).

Furthermore, the absence of TRIP8b was accompanied by a shift of the half-maximal activation of $I_{\mathrm{h}}\left(V_{0.5}\right)$ to more hyperpolarized values (WT VB, $-84.7 \pm 1.2 \mathrm{mV}, n=9$ cells and TRIP8b ${ }^{-1-} \mathrm{VB},-93.4 \pm 1.2 \mathrm{mV}, n=10$ cells, $p<0.001$; WT PO, $-84.6 \pm 1.1 \mathrm{mV}, n=9$ cells and TRIP8b $^{-l-}$ PO $,-90.3 \pm 1.01 \mathrm{mV}, n=8$ cells, $p<0.001$; WT CM, $-83.2 \pm 2.3 \mathrm{mV}, n=8$ cells and TRIP8b ${ }^{-1-}$ $\mathrm{CM},-94.3 \pm 2.5 \mathrm{mV}, n=6$ cells, $p<0.001$; WT dLGN, $-85.7 \pm 2.2 \mathrm{mV}, n=9$ cells and TRIP8b ${ }^{-/-}$dLGN, $-92.1 \pm 2.1, n=8$ cells, $p<0.05$; see Supplemental Fig. $7 \mathrm{~b}$ and $\mathrm{c})$. 
Since time-dependent activation kinetics represent a sensitive measure for the subunit composition and cyclic nucleotide-dependent modulation of HCN channels, we determined time constants of $I_{\mathrm{h}}$ activation. Under the current recording conditions, channel opening was best approximated by a double exponential equation. The deletion of TRIP8b slowed down both the fast $\left(T_{1}\right)$ and the slow $\left(T_{2}\right)$ components of time-dependent $I_{\mathrm{h}}$ activation. Results are presented in Supplemental Table 1.

Since HCN channel properties in the rodent thalamus change during development (Kanyshkova et al. 2009, 2012), $I_{\mathrm{h}}$ was assessed in TC neurons of 3-4-month old animals. The results presented in Supplemental Figure 8 show an age-dependent negative shift in the voltage-dependent activation of $I_{\mathrm{h}}$ (WT VB TC neurons, $V_{0.5}$ from $-84.7 \pm 0.8 \mathrm{mV}$ in 15-30-day-old mice to - $91.2 \pm 1.2 \mathrm{mV}$ in 90-120-day-old animals, $n=9 / 6$ cells, $p<0.001$; TRIP8b ${ }^{-1-}$ VB TC neurons, $V_{0.5}$ from $-93.4 \pm 0.9 \mathrm{mV}$ in 15-30-day-old to $-99.2 \pm 2 \mathrm{mV}$ in 90-120-day-old animals, $n=10 / 7$ cells, $p<0.05$; see Supplemental Figure 8a-d) accompanied by a slight increase in the current density (data not shown), in both $\mathrm{TRIP} \mathrm{b}^{-1-}$ and WT animals. In addition, $I_{\mathrm{h}}$ showed a slower activation time constant in TRIP8 $\mathrm{b}^{-/-}$of both age groups (see Supplemental Figure 8e).

These data indicate that TRIP8b regulates the functional expression of HCN channels and their steady-state and kinetic in thalamic neurons throughout postnatal development.

\section{Lower intracellular cAMP levels in the absence of TRIP8b}

Since modulation by cAMP is a characteristic property of HCN channels and TRIP8b has been shown to interfere with this mechanism (Zolles et al. 2009; $\mathrm{Hu}$ et al. 2013), we manipulated intracellular cAMP levels in the following. Currents measured during application of different concentrations of 8-bromo (Br)-cAMP via the patch pipette. 8-BrcAMP induced a dose-dependent depolarizing shift in voltage-dependent activation of $I_{\mathrm{h}}$ in both TRIP8b ${ }^{-1-}$ - and WTderived TC neurons (Supplemental Figure 9a-c). However, the effect of cAMP revealed differences with respect to sensitivity and efficacy in the two strains. Application of 8-Br-cAMP induced a pronounced positive shift in $V_{0.5}$ already at lower concentrations in TRIP8b ${ }^{-/-}$compared to WT mice, suggesting a higher cAMP sensitivity of $\mathrm{HCN}$ channels in the absence of TRIP8b. Interestingly, in both genotypes $V_{0.5}$ at $100 \mu \mathrm{M}$ 8-Br-cAMP was shifted to a similar depolarized value of $-66.3 \mathrm{mV}$ in WT and - 66.1 mV in TRIP8b ${ }^{-1-}$ TC neurons (Supplemental Figure $9 \mathrm{a}$ and $\mathrm{c} ; n=9 / 6)$. The maximal depolarizing shift, however, was larger in TRIP8b ${ }^{-1-}$ neurons $\left(\Delta V_{0.5}=\right.$ $27.2 \mathrm{mV}$; from -93.3 to $-66.1 \mathrm{mV}$ ) than in WT neurons from $\Delta V_{0.5}=18.4 \mathrm{mV} ;-84.7$ to $-66.3 \mathrm{mV}$ indicating a higher cAMP efficacy in the absence of TRIP8b. In addition, 8-Br-cAMP induced an increase in $I_{\mathrm{h}}$ current density only in WT TC neurons without changing this parameter in TRIP8b $^{-1-}$ TC neurons (Supplemental Figure 9d). Based on the increased cAMP sensitivity of $I_{\mathrm{h}}$ in TRIP8 $\mathrm{b}^{-/-}$mice, we expected their control values of $V_{0.5}$ to be more depolarized under resting conditions in comparison to WT animals. To test for possible changes in the basal intracellular cAMP levels in TC neurons from TRIP8b ${ }^{-1-}$ mice, we used the adenylyl cyclase inhibitor SQ22536. Incubation of thalamic slices with SQ22536 (200 $\mu \mathrm{M}, 1.5 \mathrm{~h})$ shifted the activation curve of $I_{\mathrm{h}}$ to more hyperpolarizing potentials in TC neurons of WT but not TRIP8b ${ }^{-1-}$ mice (ANOVA's followed by Student's $t$ tests, WT: $V_{0.5}$ from $-84.7 \pm 0.8$ to $-91.8 \pm 1.2 \mathrm{mV}, n=8 / 7$ cells, $p<0.001$ TRIP8b $^{-/-}$: $V_{0.5}$ from $-93.0 \pm 1.8 \mathrm{mV}$ to $-93.7 \pm 2.0 \mathrm{mV}, n=11 / 7$ cells, $p>0.05$; Fig. 4a). Furthermore, time constants of $I_{\mathrm{h}}$ activation were slower in SQ22536-treated groups as compared to non-treated controls (ANOVA's followed by Student's $t$ tests, $p$ 's $<0.05$ for fast and slow components of $I_{\mathrm{h}}$ activation, see Fig. 4b).

Next, we tested the effect of the adenosine $A_{1}$ receptor agonist CCPA which is known to cause adenylyl cyclase inhibition and thereby reducing intracellular cAMP levels (van Calker et al. 1979; Pape 1992). As shown in Fig. 4c, $\mathrm{d}$, bath application of $100 \mu \mathrm{M}$ CCPA shifted the voltagedependent activation of $I_{\mathrm{h}}$ to more hyperpolarized potentials in both, WT and TRIP8b ${ }^{-1-}$ TC neurons. The effect was stronger for TC neurons from WT compared to TRIP8b $^{-1-}$ mice (Fig. 4d, left panel; WT: $V_{0.5}$ from $-87.6 \pm 1.1 \mathrm{mV}$ to $-102.5 \pm 1.15 \mathrm{mV}, n=5$ cells, $p<0.001$; TRIP8b ${ }^{-1-:} V_{0.5}$ from $-96.18 \pm 1.1 \mathrm{mV}$ to $-102.5 \pm 1.3 \mathrm{mV}, n=6$ cells, ANOVA's followed by Student's $t$ tests, $p$ 's $<0.05)$. In addition, $\Delta V_{0.5}$, the shift in $V_{0.5}$ produced by application of $100 \mu \mathrm{M}$ CCPA, was significantly smaller in TC neurons from $\mathrm{TRIP}^{-1-}$ compared to WT mice (Fig. 4d, middle panel; $\Delta V_{0.5}=$ $6.3 \pm 1.7 \mathrm{mV}$ in TRIP8b ${ }^{-1-}$ and $\Delta V_{0.5}=14.9 \pm 1.76-$ $\mathrm{mV}$ in WT, $n=6 / 5$ cells, $\mathrm{p}<0.01)$. Moreover, application of CCPA decreased $I_{\mathrm{h}}$ current density measured at the step to $-130 \mathrm{mV}$ (Fig. 4d, right panel; WT TC neurons: from $15.0 \pm 3.1 \mathrm{pA} / \mathrm{pF}$ to $10.9 \pm 2.9 \mathrm{pA} / \mathrm{pF}, n=5$ cells, $p<0.05$, TRIP8b ${ }^{-1-}$ TC neurons: from $4.9 \pm 0.7 \mathrm{pA} / \mathrm{pF}$ to $3.0 \pm 0.5, n=6$ cells, $p<0.05)$ and also slowed down the fast and slow components of $I_{\mathrm{h}}$ activation kinetics in both groups (Repeated-measures ANOVA showed a significant main effect of CCPA application on time constants: $p<0.05$ for fast and slow components of $I_{\mathrm{h}}$, respectively; data not shown).

In line with the results of a previous study (Heuermann et al. 2016), these results indicate an increased cAMP sensitivity of $I_{\mathrm{h}}$ in TC neurons from TRIP8b ${ }^{-1-}$ mice. Furthermore, there seems to be a lower basal adenylyl cyclase 

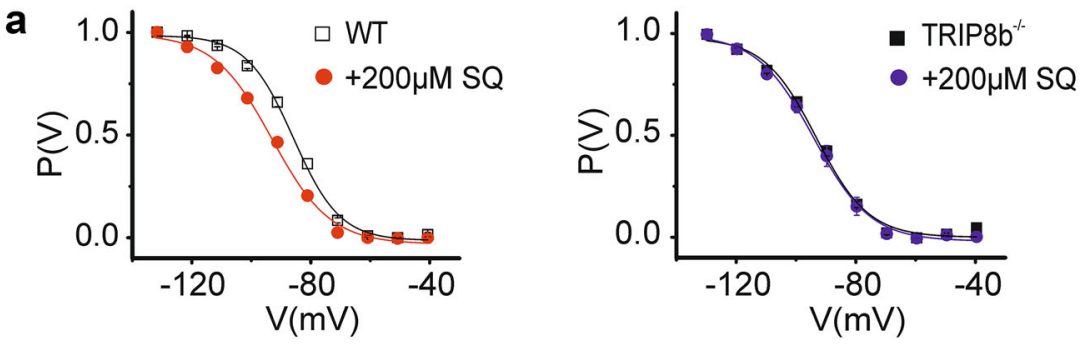

b
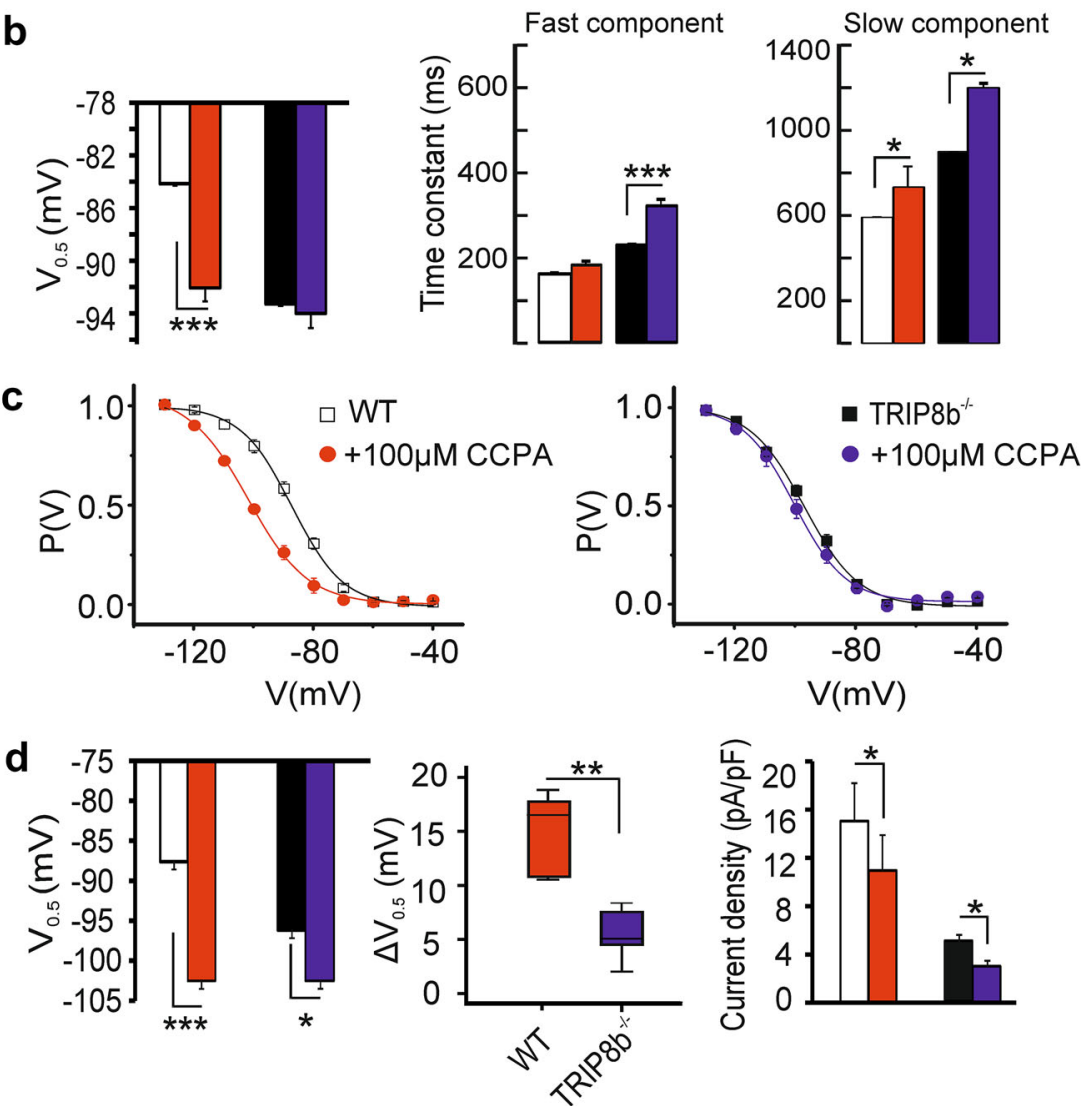

Fig. 4 Modulation of $I_{h}$ in TC neurons by cAMP. a Graphs showing the mean steady-state activation curves of $I_{\mathrm{h}}$ in thalamocortical (TC) neurons of WT ( $n=8 / 7$ cells) and TRIP8b ${ }^{-1-}(n=11 / 8$ cells $)$ mice. Slices were incubated either with $200 \mu \mathrm{M}$ (dots) or without (squares) the adenylyl cyclase inhibitor SQ22536. Incubation with SQ22536 shifted the voltage-dependent activation $\left(V_{0.5}\right)$ of $I_{\mathrm{h}}$ to more hyperpolarizing potentials without having any effects on $I_{\mathrm{h}}$ in TRIP8b $^{-l-}$ TC neurons (left panel, ANOVA followed by Student's $t$ tests, $* * *$ indicates $p<0.001$ ). b (middle and right panel) The activation kinetics of $\mathrm{I}_{\mathrm{h}}$ in both TRIP8 $\mathrm{b}^{-/-}$and WT TC neurons were slowed down in SQ22536 treated cells. c Graphs showing the mean activity in TC neurons from TRIP8b ${ }^{-1-}$ mice which results in reduced basal cAMP concentrations, hyperpolarized RMP and smaller effects of $\mathrm{G}_{\mathrm{i}}$-coupled receptors.

To further address this possibility, we assessed basal cAMP levels in brain tissue samples (Supplemental Figure 9e). Quantification of cAMP concentration from 3 -month old WT and TRIP8 $\mathrm{b}^{-1-}$ mice revealed a significantly lower cAMP level in knockout animals compared to $\mathrm{WT}$ animals $(\mathrm{WT}=27.0 \pm 4 \mathrm{pmol} \mathrm{cAMP} / \mathrm{mg}$ protein, steady-state activation curves of $I_{\mathrm{h}}$ in WT $(n=5$ cells) and TRIP8b $^{-l-}$ ( $n=6$ cells) TC neurons of the VB complex following bath application of $100 \mu \mathrm{M}$ CCPA (dots). d Although CCPA shifted the voltage-dependent activation of $I_{\mathrm{h}}$ to negative potentials in both groups (left panel), the hyperpolarizing shift in $V_{0.5}$ of $I_{\mathrm{h}}\left(\Delta V_{0.5}\right.$, middle panel) in thalamic relay neurons of TRIP8b ${ }^{-1-}$ mice was significantly smaller compared to WT TC neurons. The reduction in $I_{\mathrm{h}}$ current density after application of CCPA in both groups is depicted in the bar graph (right panel). Repeated-measures ANOVA followed by Student's $t$ tests, *, **, *** indicate $p<0.05, p<0.01$, and $p<0.001$, respectively

$\mathrm{TRIP} 8 \mathrm{~b}^{-/-}=13.2 \pm 2.1 \mathrm{pmol} \mathrm{cAMP} / \mathrm{mg}$ protein, $n=3 /$ 3 animals, total of 18 samples, $p<0.01$ ).

\section{Changes in firing pattern and intrinsic properties of TC neurons in TRIP8b ${ }^{-/-}$mice}

To determine the functional impact of TRIP8b on passive membrane properties and neuronal firing, VB TC neurons were recorded under current-clamp conditions. Since tonic 
a

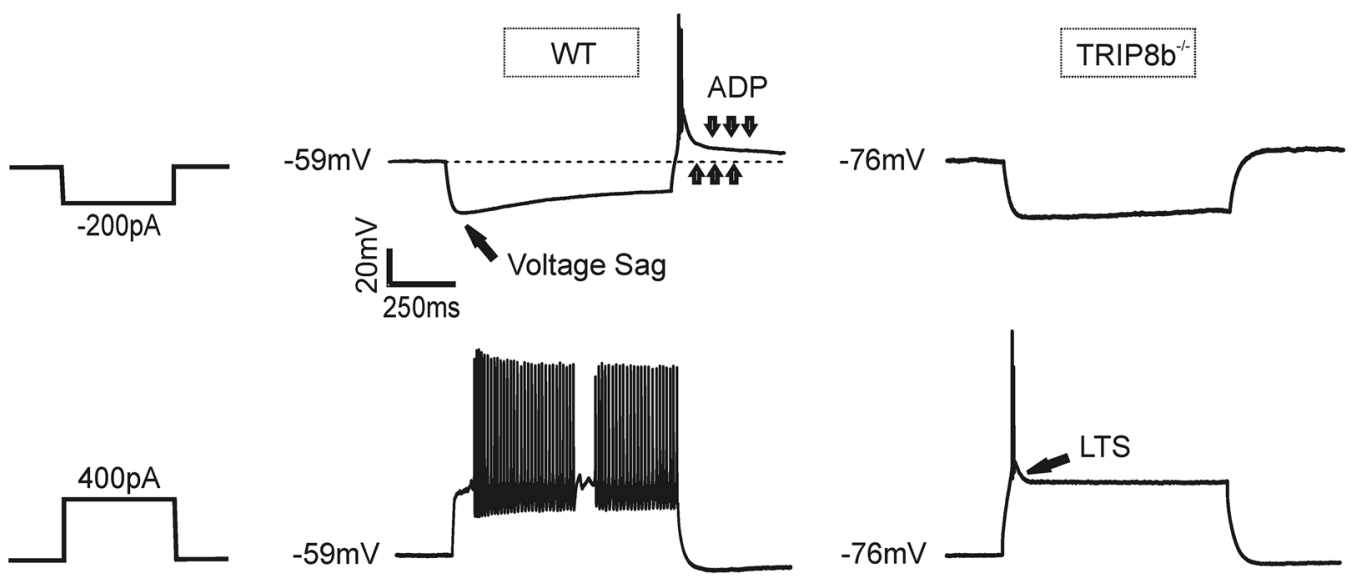

b

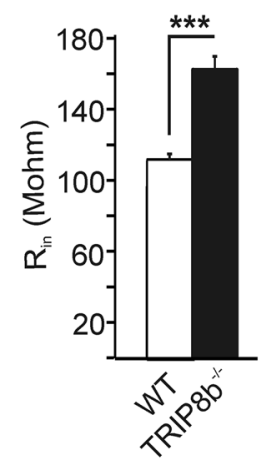

f

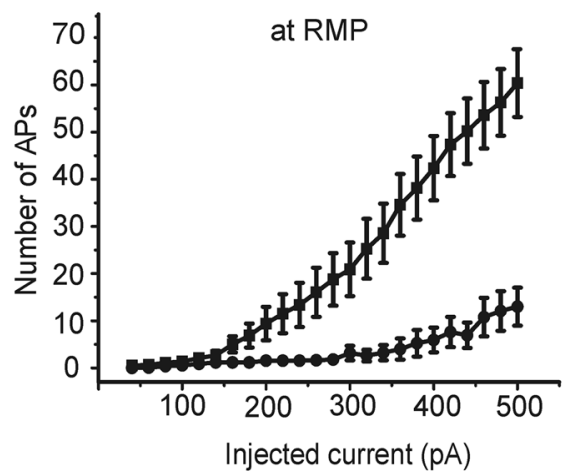

d

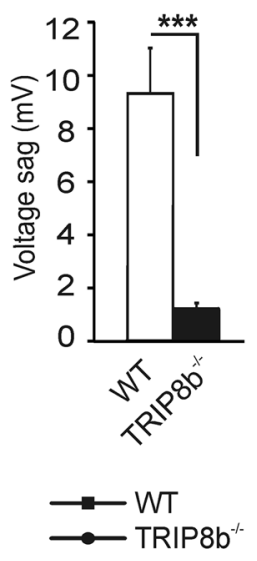

g

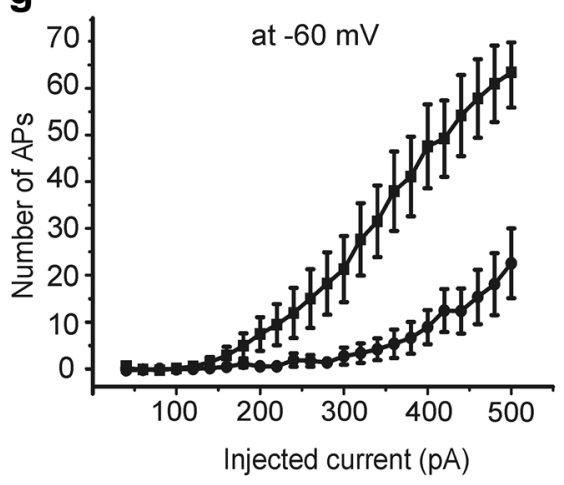

h

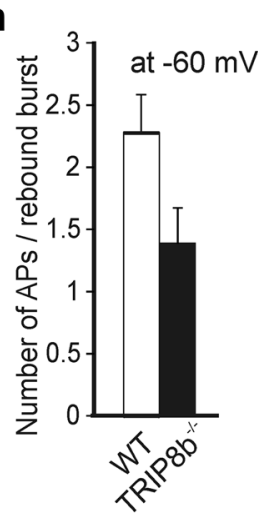

$I_{\mathrm{h}}$ activity influences passive membrane properties, we analyzed $R_{\mathrm{in}}$ and RMP. Indeed the reduction of $I_{\mathrm{h}}$ was accompanied by an increase in $R_{\text {in }}$ (Fig. 5b; WT: $110.2 \pm 3 \mathrm{M} \Omega ;$ TRIP8b $^{-1-}: 160.5 \pm 8 \mathrm{M} \Omega ; n=22 / 13$ cells, $p<0.001$ ) and a hyperpolarizing shift in RMP (Fig. 5c; WT: $\quad-64.3 \pm 1.9 \mathrm{mV} ; \quad$ TRIP8b $^{-1-}$ : $-75.2 \pm 1.8 \mathrm{mV}, \quad n=22 / 13$ cells, $p<0.001)$. The occurrence of the two prototypical firing patterns of TC neurons in rodents, namely burst and tonic firing, depends on the level of the prevailing membrane potential (Fig. 5a). Following depolarizing current pulses, TC neurons generate bursts of APs riding on top of a low-threshold $\mathrm{Ca}^{2+}$ spike (LTS; see arrow in Fig. 5a lower right panel) and tonic activity when the prevailing membrane potential is below $-70 \mathrm{mV}$ and above $-60 \mathrm{mV}$, respectively (Cerina et al. 2015; Bista et al. 2015b; Llinas and Steriade 2006). In 
4Fig. 5 Changes in firing pattern and intrinsic properties of the TC neurons in TRIP8b ${ }^{-1-}$ mice. a Sample traces recorded in response to the injection of hyperpolarizing and depolarizing currents from the RMP of TC neurons in the VB complex of WT and TRIP8b $\mathrm{b}^{-1-}$ mice. Note the different behavior of cells in response to the positive and negative current injections. LTS (see arrow, lower right panel) and ADP (3 downward arrows, upper panel) represent low-threshold $\mathrm{Ca}^{2+}$ spike and $\mathrm{I}_{\mathrm{h}}$-dependent afterdepolarizing potential, respectively. The 3 upward arrows indicate RMP. b and $\mathbf{c}$ show the higher $\mathrm{R}_{\text {in }}$ and significantly hyperpolarized RMP of TC neurons in TRIP8b ${ }^{-1-}$ compared to WT mice (Student's $t$ tests. ** and $* * *$ indicate, $p<0.01$ and $p<0.001$, respectively). d Bar graph showing a significant reduction in the $I_{\mathrm{h}}$-dependent voltage sag in TRIP8b ${ }^{-1-}$ (Student's $t$ tests, $* * *$ indicates $p<0.001)$. The voltage sag was measured upon injection of a hyperpolarizing current of $-200 \mathrm{pA}$. e Pie charts indicating the percentage (\%) of burst activity in TC neurons of TRIP8b $\mathrm{b}^{-1-}(72 \%, n=14$ cells $)$ compared to WT mice ( $41 \%, n=22$ cells), when cells were challenged with depolarizing currents from RMP (left panels). The occurrence of burst firing was no longer different between the two groups when TC neurons were held at a more depolarized potential of around $-60 \mathrm{mV}$ by $\mathrm{DC}$ current injection (right panels). $\mathbf{f}$ The number of APs elicited by the injection of positive currents with $20 \mathrm{pA}$ increments from RMP is shown. Significantly (Repeated-measures ANOVA, $p<0.001$ ) less APs were evoked in TRIP8b ${ }^{-1-}$ TC neurons. $g$ The number of depolarization-induced APs in TRIP8b ${ }^{-1-}$ TC neurons after compensation of the membrane hyperpolarization by injection of a small positive DC current (holding the RMP at $-60 \mathrm{mV}$ ) was still significantly (repeated-measures ANOVA, $p<0.001$ ) lower compared to the WT TC neurons. $\mathbf{h}$ Bar graph comparing the number of APs on rebound burst in WT and TRIP $8 \mathrm{~b}^{-1-} \mathrm{VB}$ TC neurons

the voltage range between -70 and $-60 \mathrm{mV}$ burst and tonic firing may be intermingled. Bursting may also occur following release from a hyperpolarizing pulse in the form of a rebound burst (see Fig. 5a upper panel). During the course of negative voltage deflections, another hallmark of $I_{\mathrm{h}}$ activation is triggered, namely the depolarizing voltage sag (see arrow in Fig. 5a upper panel). In accordance with the reduction in $I_{\mathrm{h}}$, negative current injections $(-200 \mathrm{pA}$, $1000 \mathrm{~ms}$ ) from the RMP induced voltage sags which were significantly smaller in the absence of TRIP8b (Fig. 5d; WT VB: $9.3 \pm 2.2 \mathrm{mV}$; TRIP8b ${ }^{-/-}$VB: $1.1 \pm 1.7 \mathrm{mV}$; $n=22 / 13$ cells, Student's $t$ test, $p<0.001)$. Interestingly, injection of hyperpolarizing currents to TC neurons of $\mathrm{TRIP}^{-1-}$ mice did not elicit the typical rebound burst and $I_{\mathrm{h}}$-dependent afterdepolarizing potential (ADP) which occurs due to deactivation of HCN channels (Fig. 5a upper right panel), probably because the threshold for activation of T-type $\mathrm{Ca}^{2+}$ channels is not reached due to the negative RMP. Indeed, rebound bursts reappeared with the same amount of hyperpolarizing current injections while holding the cells at $-60 \mathrm{mV}$, yet, the number of APs triggered by the LTS was lower in TRIP8b ${ }^{-/-}$mice (Fig. 5h). When TC neurons in TRIP8b ${ }^{-l-}$ mice were challenged with depolarizing currents from RMP, burst activity was more frequently elicited in comparison to WT mice (Fig. 5a lower panel and e). As illustrated in Fig. 5e, injection of depolarizing currents to TRIP8b $\mathrm{b}^{-1-}$ TC neurons from RMP resulted in burst activity in $72 \%$ of the cells $(n=14)$ compared to $41 \%$ in WT TC neurons $(n=22, p<0.01)$. To further assess tonic firing properties, TC neurons were held at a more depolarized potential of around $-60 \mathrm{mV}$ by DC current injection. Under these conditions, the occurrence of burst firing was no longer different between the two groups (Fig. 5e right panel). In accordance with the predominance of bursting, the total number of APs generated by depolarizing pulses was lower in TC neurons from TRIP8b $^{-1-}$ in comparison to WT mice (Fig. 5f). However, $\mathrm{TRIP}^{-1-} \mathrm{TC}$ neurons still showed a significantly lower total number of tonic APs than WT neurons after injection of depolarizing currents (Fig. $5 \mathrm{~g}$ ).

Since $I_{\mathrm{h}}$ density sets the level of the membrane potential, thereby influencing tonic firing patterns in thalamic interneurons (Leist et al. 2016), we tried to mimic the effects of TRIP8b loss by applying the HCN channel blocker ZD7288. To further strengthen the conclusion that the changes in RMP and firing properties seen in VB TC neurons in TRIP8b ${ }^{-1-}$ can be explained by reduction of $I_{\mathrm{h}}$, WT mice were investigated under current-clamp conditions in the presence of $10 \mu \mathrm{M}$ ZD7288. This concentration was chosen based on previous experiments under voltage-clamp conditions where $10 \mu \mathrm{M}$ ZD7288 reduced $I_{\mathrm{h}}$ current density to a level very similar to that found in TRIP8b ${ }^{-1-}$ mice (Fig. 6a). As illustrated in Fig. 6c-e, application of ZD7288 under current-clamp conditions resulted in a significant decrease in the $I_{\mathrm{h}}$ voltage sag (Fig. 6c; from $14.5 \pm 5.21 \mathrm{mV}$ to $1.7 \pm 0.8 \mathrm{mV}, n=6$ cells, $p<0.001)$ and a significant hyperpolarizing shift in the RMP (Fig. 6d; from -60.03 \pm 1.8 to $-69.8 \pm 1.7 \mathrm{mV}, n=6$ cells, $p<0.01)$, accompanied by an increase in the input resistance of the cells (Fig. 6e; from $125.8 \pm 3.7$ to $158.83 \pm 4.23 \mathrm{M} \Omega$, $n=6$ cells, $p<0.001)$. Only two out of six cells showed a rebound burst after application of ZD7288 and the number of APs superimposed on the LTS was significantly lower (APs on LTS, $3.5 \pm 0.8$ before and $0.8 \pm 0.5$ after application of ZD7288, $n=6$ cells, $p<0.05$, data not shown). Moreover, ZD7288 increased the probability of burst firing from RMP after injection of positive currents (data not shown) and decreased tonic firing when cells were depolarized to - $60 \mathrm{mV}$ (Fig. 6f; Repeated Measures ANOVA showed a significant interaction between groups and positive current injection, $p<0.001$, and a significant main effect for groups $p<0.01)$. Previous studies have reported ZD7288 as a potent blocker of Nav1.4 (Wu et al. Wu et al. 2012) and in higher concentrations $(>100 \mu \mathrm{M})$ of low-voltage-activated calcium channels (Felix et al. 2003; Sánchez-Alonso et al. 2008), thereby characterizing this drug as a non-selective blocker for HCN channels. Considering that Nav1.4 channels are not present in rodent thalamic neurons (Kirchhof et al. 2015) and based on the fact that we applied $10 \mu \mathrm{M}$ 

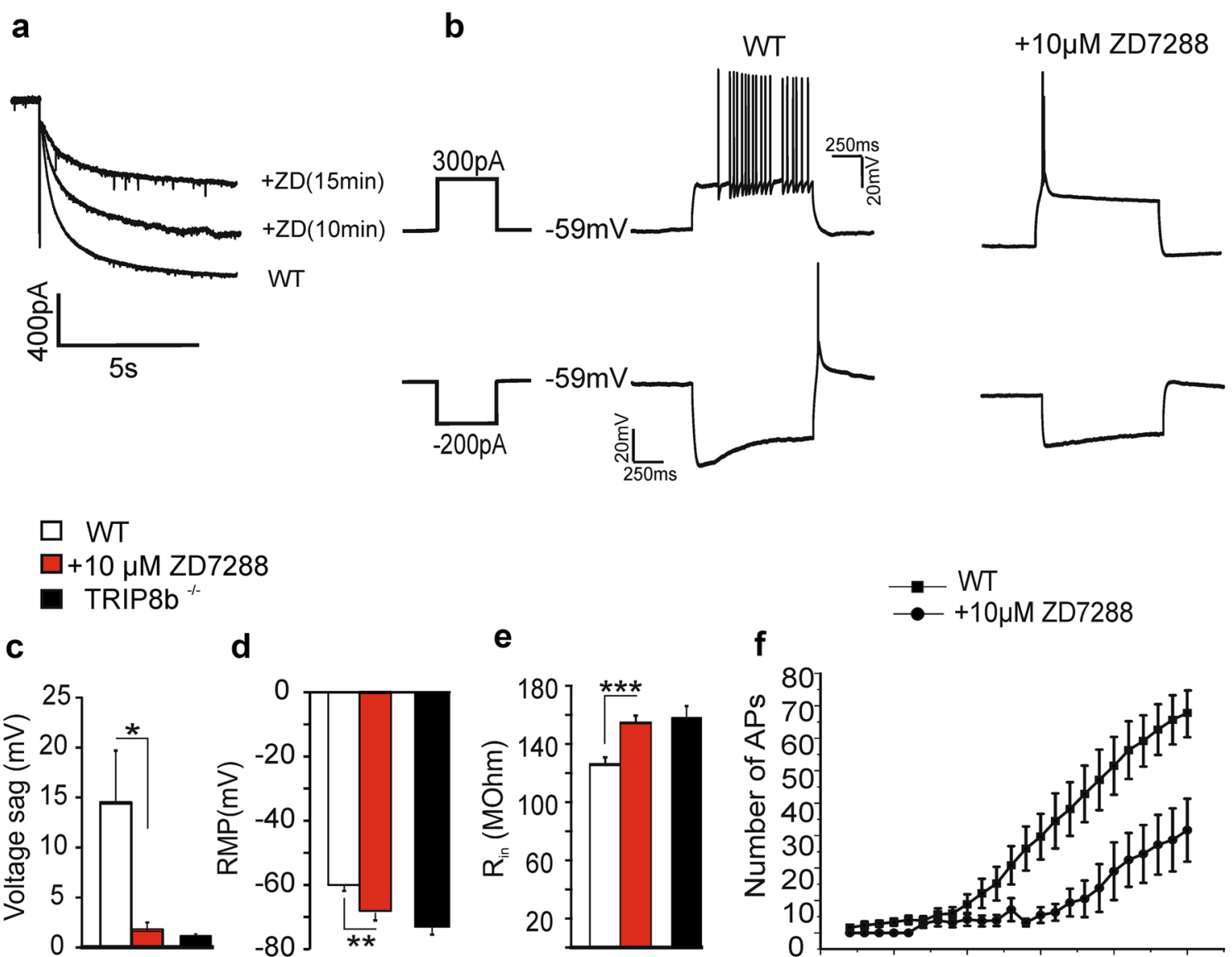

d
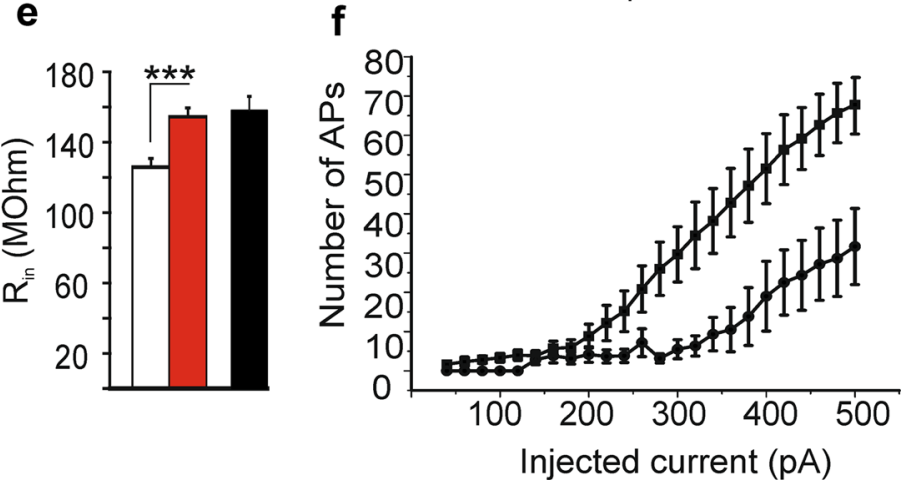

Fig. 6 Reduction of $I_{\mathrm{h}}$ in thalamic relay neurons by ZD7288. a Sample traces recorded under voltage-clamp conditions in the presence of $10 \mu \mathrm{M}$ ZD7288 from TC neurons of the VB complex of WT mice. The reduction of $I_{\mathrm{h}}$ after 15 min of blocker application resembles the $I_{\mathrm{h}}$ amplitude in TRIP8b ${ }^{-1-}$ mice (see Supplemental Figure 7). b Sample traces obtained from current-clamp recordings demonstrating the changes in firing pattern and RMP of TC neurons following application of $10 \mu \mathrm{M}$ ZD7288. $\mathbf{c}$ Bar graph showing the significant reduction in the voltage sag upon current injection of

ZD7288 (thus having little effect on low-voltage-activated calcium channels), the reduction of tonic firing of TC neurons seems to be mainly based on the block of HCN channels.

These results indicate that TRIP8b is necessary for the generation of tonic currents through HCN channels, thereby influencing passive and active membrane properties of TC neurons. Furthermore, the effects of TRIP8b knockout on firing pattern and intrinsic properties of TC neurons are largely reproduced by pharmacological reduction of $I_{h}$.

\section{Analysis of the fast transient potassium outward current in TRIP8b $^{-1-}$ mice}

Since $I_{\mathrm{A}}$ is known to shape bursting as well as tonic firing of TC neurons (Pape et al. 1994; Kanyshkova et al. 2011),
$-200 \mathrm{pA}(n=6)$. The reduction in the voltage sag is comparable with the values obtained from TRIP8b ${ }^{-l-}$ relay neurons. The reduction in $I_{\mathrm{h}}$ density is accompanied by a significant (ANOVAs, $p<0.001)$ shift to hyperpolarizing potentials in RMP of WT TC neurons (d) and an increase in $R_{\text {in }}(\mathbf{e})$. As shown in (f) the number of APs elicited by the injection of positive currents with $20 \mathrm{pA}$ increment from RMP after bath application of ZD7288 (filled circles) is significantly smaller (ANOVAs, $p<0.001$ ) than under control conditions (filled squares)

we characterized this outward current in the following. To elicit $I_{\mathrm{A}}$, cells were held at a potential of $-69 \mathrm{mV}$ followed by hyperpolarization to a conditioning potential of $-129 \mathrm{mV}$ ( $2 \mathrm{~s}$ duration) before stepping to various test potentials ( -99 to $+21 \mathrm{mV} ; 10 \mathrm{mV}$ increment; $200 \mathrm{~ms}$ duration; see Fig. 7a, left panel). To minimize the contribution of delayed rectifier $\mathrm{K}^{+}$channels, we added TEA $(10 \mathrm{mM})$ to the external solution. Furthermore, voltagedependent $\mathrm{Na}^{+}$channels were blocked with TTX $(1 \mu \mathrm{M})$ and $\mathrm{Ca}^{2+}$ currents were eliminated using $\mathrm{Ca}^{2+}$-free (+ $1 \mathrm{mM}$ EGTA) extracellular solutions (Budde et al. 1992). Under these conditions, outward current amplitudes rapidly increased with increasing step depolarization and the current waveform revealed a characteristic initial peak within less than $10 \mathrm{~ms}$ (Fig. 7a, right panel). To allow 

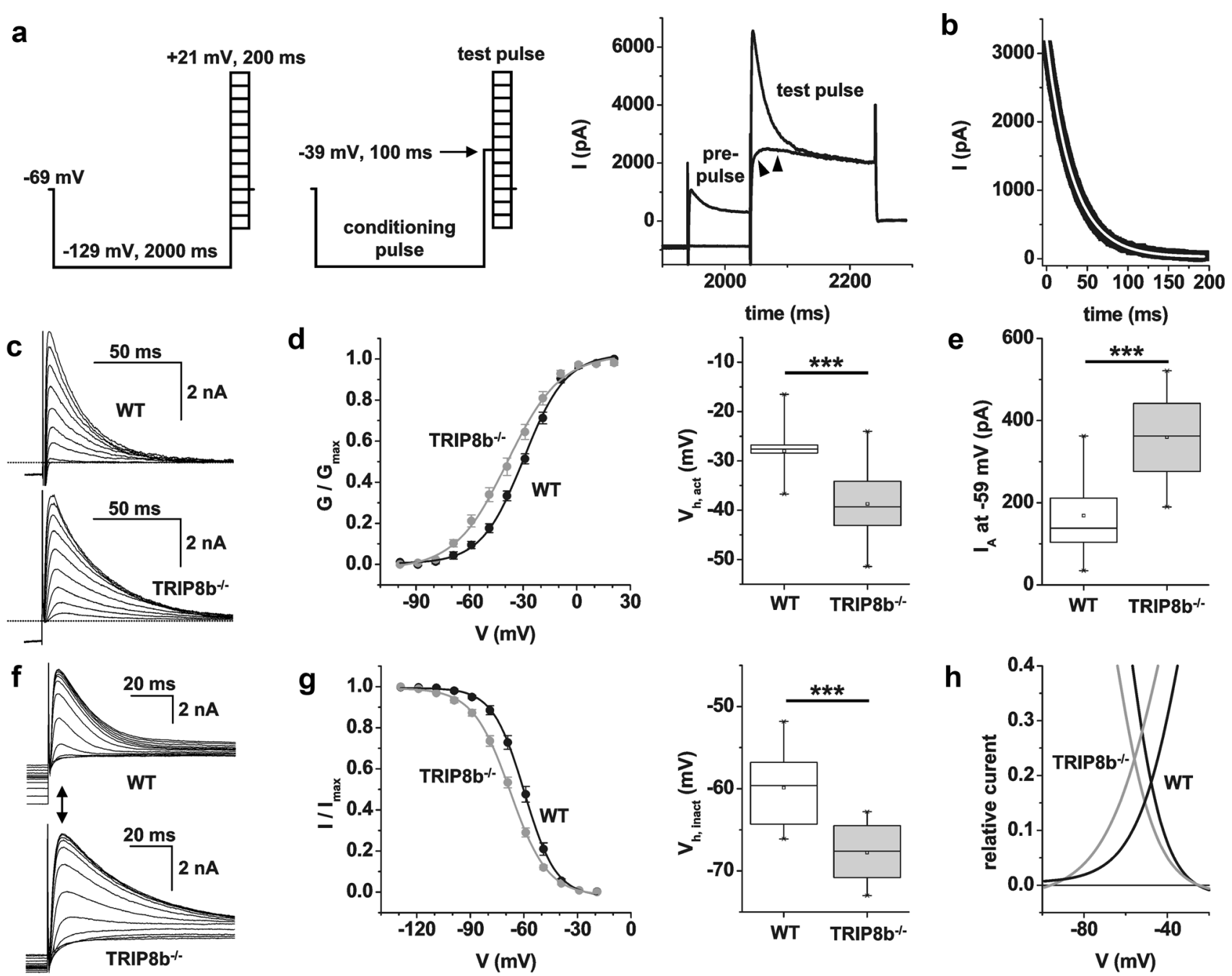

Fig. 7 Voltage-dependent properties of $I_{\mathrm{A}}$ in TC neurons of WT and TRIP8b $^{-1-}$ mice. a Voltage protocols to isolate $I_{\mathrm{A}}$. Cells were set to a conditioning potential ( $2 \mathrm{~s}$ duration) of $-129 \mathrm{mV}$ before stepping to varying depolarizing potentials $(-99$ to $+21 \mathrm{mV}, 200 \mathrm{~ms}$ duration; left panel) to evoke outward currents. Then, the voltage protocol was repeated with a pre-pulse to $-39 \mathrm{mV}$ (100 ms duration; see arrow) inserted between the conditioning and the test pulse (middle panel). Inclusion of the pre-pulse resulted in complete disappearance of the transient outward current component during the test pulse (see arrow heads in the right panel; traces of test pulses to $+21 \mathrm{mV}$ in a WT animal with and without pre-pulse are shown). The pre-pulsesensitive current component was obtained by graphical subtraction of current with and without pre-pulse. b The decay of a pre-pulsesensitive current to $+1 \mathrm{mV}$ in a WT mouse is best fitted by a single exponential function with $\tau=33 \mathrm{~ms}$. c Families of transient outward currents obtained by graphical subtraction in WT (upper panel) and TRIP8b $^{-1-}$ (lower panel) mice. Dashed lines indicate the zero line. d Activation curves of $I_{\mathrm{A}}$ in WT (black symbols) and TRIP8b ${ }^{-/-}$ (gray symbols) mice were obtained through Boltzmann fits of relative

isolation of $I_{\mathrm{A}}$, a pre-pulse protocol was used (Fig. 7a, middle panel). Therefore, a step to $-39 \mathrm{mV}$ (100 ms duration) was placed between the hyperpolarizing condition pulse and the test pulse. In WT mice, the current sensitive to the inclusion of the pre-pulse was obtained by conductance values (left panel). Box plot representation of halfmaximal activation values in WT (white box) and TRIP8b ${ }^{-1-}$ (gray box) mice (right panel). e Box plot representation of $I_{\mathrm{A}}$ current amplitudes at a test potential of $-59 \mathrm{mV}$ in WT (white box) and $\mathrm{TRIP}^{-1-}$ (gray box) mice (right panel). f Inactivation of $I_{\mathrm{A}}$ was determined by varying a 2 s conditioning pulse between -129 and $-19 \mathrm{mV}$, and keeping the following test potential constant at - $9 \mathrm{mV}$ (200 ms duration). Families of transient outward currents in WT (upper panel) and TRIP8b ${ }^{-1-}$ (lower panel) mice are shown. Peak current amplitudes within $15 \mathrm{~ms}$ after stepping to the test pulse potential were determined (see double arrow). $\mathbf{g}$ Inactivation curves of $I_{\mathrm{A}}$ in WT (black symbols) and TRIP8b ${ }^{-1-}$ (gray symbols) mice were obtained through Boltzmann fits of relative current values (left panel). Box plot representation of half-maximal inactivation values in WT (white box) and TRIP8b ${ }^{-1-}$ (gray box) mice (right panel). h Combined Boltzmann fits (as in $\mathbf{d}$ and $\mathbf{g}$ ) of activation and inactivation curves in WT (black lines) and TRIP8b ${ }^{-1-}$ (gray lines) mice reveal an area of overlap, the $I_{\mathrm{A}}$ window current. Please note that more current is available in TRIP8b ${ }^{-1-}$ mice

graphical subtraction (control-pre-pulse) and peaked within 3-8 ms and completely inactivated with a single time constant of $34.8 \pm 2.5 \mathrm{~ms}(n=15$ cells; for the step to $+1 \mathrm{mV}$; Fig. $7 \mathrm{~b}$ ) thereby revealing the typical kinetic properties of $I_{\mathrm{A}}$ in VB TC neurons (Huguenard et al. 1991). 
In TRIP8b ${ }^{-1-}$ mice, the time constant of inactivation was significantly $(p<0.05)$ faster $\left(\tau_{\text {inact }}=28.0 \pm 1.5 \mathrm{~ms}, n=\right.$ 14; data not shown).

The voltage dependency of activation of $I_{\mathrm{A}}$ was investigated by analyzing the peak current amplitudes at all test potentials (Fig. 7c) and constructing steady-state activation curves from the normalized conductance values (Fig. 7d). Comparison between genotypes revealed an activation threshold negative to $-70 \mathrm{mV}$ and $V_{\mathrm{h}}$ values which were significantly $(p<0.001)$ different between WT $\left(V_{\mathrm{h}}=\right.$ $-28.0 \pm 1.5 \mathrm{mV}, n=11$ cells $)$ and $\mathrm{TRIP}^{-1-}\left(V_{h}=-\right.$ $38.7 \pm 2.1 \mathrm{mV}, n=11$ cells; Fig. 7e) mice. The hyperpolarizing shift in the activation curve lead to an increased availability of $\mathrm{I}_{\mathrm{A}}$ in $\mathrm{TRIP}^{-1-}$ mice at subthreshold $\left(-59 \mathrm{mV}\right.$; WT: $168.6 \pm 23.8 \mathrm{pA}, n=16$ cells; $^{\text {TRIP8b }}{ }^{-1-}$ : $359.3 \pm 27.5 \mathrm{pA}, n=14$ cells; $p<0.001)$ but not depolarized membrane potentials $(+1 \mathrm{mV}$; WT: $2758.0 \pm 283.2$ pA, $n=16$ cells; TRIP8b ${ }^{-/-}: 3194.8 \pm 334.6$ pA, $n=14$ cells).

Next, the steady-state inactivation was investigated by holding neurons at $-69 \mathrm{mV}$ and stepping to different conditioning potentials ( -129 to $-19 \mathrm{mV}, 2 \mathrm{~s}$ duration, $10 \mathrm{mV}$ increment), before stepping to a constant analyzing test potential of $-9 \mathrm{mV}$ of $100 \mathrm{~ms}$ duration (Fig. 7f). Steady-state inactivation curves were constructed from normalized current values. Similar to the results obtained for current activation, $V_{\mathrm{h}}$ values of steady-state inactivation were significantly more depolarized in WT $\left(V_{\mathrm{h}}=-\right.$ $59.9 \pm 1.3 \mathrm{mV}, n=11$ cells) compared to TRIP8b $^{-1-}$ $\left(V_{h}=-67.8 \pm 1.1 \mathrm{mV}, \quad n=11\right.$ cells; Fig. $\left.7 \mathrm{~g}\right)$ mice. While the more hyperpolarized inactivation in TRIP8b ${ }^{-1-}$ mice may be expected to result in less channels available for activation at a given membrane potential, the "window current" between the activation and inactivation curves revealed more tonically active $I_{\mathrm{A}}$ near the resting potential in knockout animals (Fig. 7h).

These findings indicate that alterations in $I_{\mathrm{A}}$ may contribute to the differences in firing pattern found in $\mathrm{TRIP} 8 \mathrm{~b}^{-1-}$ mice.

\section{Reduction of burst activity in thalamic network in the absence of TRIP8b}

$I_{\mathrm{h}}$ is an important determinant of oscillatory and rhythmic bursting activity of the thalamic network and has frequently been used as a measure of intrathalamic rhythmicity and possible predisposition for epileptic seizures (Kanyshkova et al. 2012; Kanyshkova et al. 2009; Budde et al. 2005). Intrathalamic network activity is mainly based on reciprocal interactions between TC neurons of dorsal thalamus and GABAergic neurons of $\mathrm{nRT}$ and is involved in the generation of different thalamic oscillations such as delta and spindle oscillations. To address the contribution of TRIP8b to evoked thalamic oscillations, dampened oscillatory activity (Fig. 8a) was induced through stimulation of the IC (Fig. 8b) and multiunit recordings were performed in the VB complex (Broicher et al. 2007; Yue and Huguenard 2001). As shown in Fig. 8, compared to WT animals, TRIP8b $\mathrm{b}^{-1-}$ mice showed a significantly lower number of bursts in response to a single stimulus (TRIP8b ${ }^{-1-}: 1.4 \pm 0.4$ bursts; WT: $6.9 \pm 0.5$ bursts; $n=8 / 8$ animals, average of 2-3 slices for each animal, $p<0.001$; Fig. 8c). In addition, the total number of spikes after stimulation (TRIP8b ${ }^{-/-}: 9.9 \pm 1.3$ spikes; WT: $65.2 \pm 3.2 ; n=8 / 8$ animals, average of $2-3$ slices for each animal, $p<0.001$; Fig. 8d) and the duration of the bursting (TRIP8b ${ }^{-1-}: 169.4 \pm 78.7 \mathrm{~ms}$; WT: $1017 \pm 109.7 \mathrm{~ms} ; n=8 / 8$ animals, $p<0.001$; Fig. $8 \mathrm{e})$ were significantly reduced in TRIP8 $\mathrm{b}^{-1-}$ compared to WT mice. Moreover, the frequency of rhythmic bursting was significantly lower in TRIP8b ${ }^{-1-}$ compared to WT mice (TRIP8b $^{-1-}$ : $2.3 \pm 0.9 \mathrm{~Hz}$; WT: $7.1 \pm 0.5 \mathrm{~Hz} ; n=8 / 8$, $p<0.001$, data not shown).

To corroborate that reduction of stimulus-induced activity in TRIP8 $\mathrm{b}^{-1-}$ results from the reduction of $I_{\mathrm{h}}$, we applied different concentrations of ZD7288 in slices from WT mice (Fig. 8a, f and g). While bath application of $10 \mu \mathrm{M}$ ZD7288 completely abolished the intrathalamic network activity (data not shown), application of $0.5 \mu \mathrm{M}$ ZD7288 led to a time-dependent bidirectional effect on thalamic network activity, with a significant initial increase in the number (WT: from $7.5 \pm 0.5$ to $11.3 \pm 1.1$ and to $11.0 \pm 1.3$ after 10 and $20 \mathrm{~min}$ of ZD7288 wash in, respectively, $p<0.01$; Fig. $8 \mathrm{a}, \mathrm{f})$ and total duration of rhythmic activity (WT: from $700 \pm 90$ to $1354 \pm 260 \mathrm{~ms}$ and to $1250 \pm 220 \mathrm{~ms}$ after 10 and $20 \mathrm{~min}$ of ZD7288 application, $p<0.01$; Fig. $8 \mathrm{~g}$ ). This effect was followed by a significant decrease in thalamic network activity after $1 \mathrm{~h}$ of ZD7288 treatment (number of bursts $2.8 \pm 0.7$; total duration of the rhythmic activity: $290 \pm 70 \mathrm{~ms} ; p<0.05$; Fig. 8f, g). The latter value was comparable to rhythmic activity measured in thalamic slices from TRIP8b ${ }^{-1-}$ mice. Moreover, the frequency of rhythmic bursting slowed down over time, i.e., from the theta $(7.0 \pm 0.5 \mathrm{~Hz})$ to delta frequency range $(2.7 \pm 0.9 \mathrm{~Hz}, p<0.01$, data not shown).

These results indicate that the level of $I_{\mathrm{h}}$ dynamically influences the frequency of thalamic network oscillations and that changes found in TRIP8b ${ }^{-/-}$mice mainly alter the delta frequency activity.

\section{Mathematical modeling of intrathalamic and thalamocortical network activity}

Since the horizontal slice preparation allows only a limited number of recurrent activity cycles following electrical stimulation, we assessed how changes in $I_{\mathrm{h}}$ induced by loss of TRIP8b influence spontaneous sustained rhythmic 
a

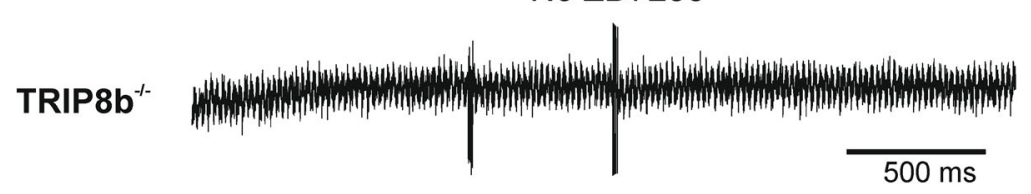

No ZD7288

WT
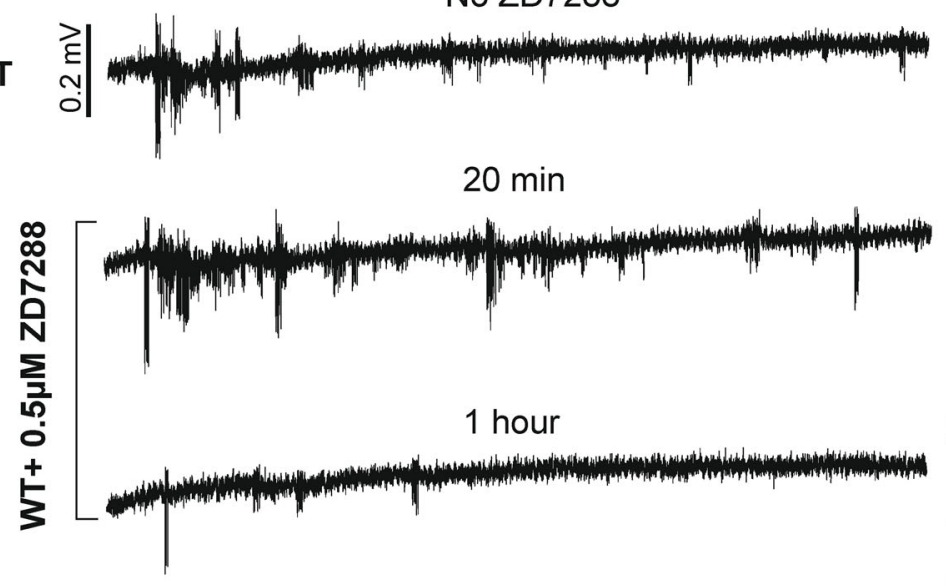

C

d
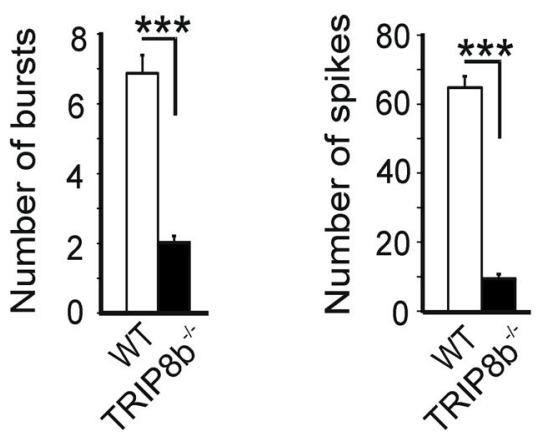

Fig. 8 Reduction of oscillatory burst activity in the thalamus of TRIP8b $^{-1-}$ mice. a Extracellular field potential recordings of burst activity in the VB complex evoked by stimulation of the IC. TRIP8 $^{-1-}$ mice $(n=8$ mice) show significantly lower numbers of evoked rhythmic bursts (Student's $t$ tests, *** indicates $p<0.001$ ) compared to WT mice $(n=8$ mice). $\mathbf{b}$ Image showing the position of recording ( $\mathrm{Re})$ and stimulation electrodes (Stm). c Bar graph comparing the mean number of bursts in VB complex of TRIP8b ${ }^{-l-}$ and WT mice in response to a single stimulus (Student's $t$ tests, *** indicates $p<0.001$ ). d Bar graph comparing the total number of

activity in the thalamocortical network using a mathematical modeling approach. Spontaneous rhythmic bursting was analyzed in a four-cell model which was used for simulation of the intrathalamic network activity (Fig. 9a) and an eight-cell model to simulate thalamocortical network activity (Fig. 9d). Simulation was initiated by releasing the TC neurons from a starting membrane potential (RMP) of $-70 \mathrm{mV}$. When the simulation was run with $I_{\mathrm{h}}$ properties determined in WT VB cells, both TC b
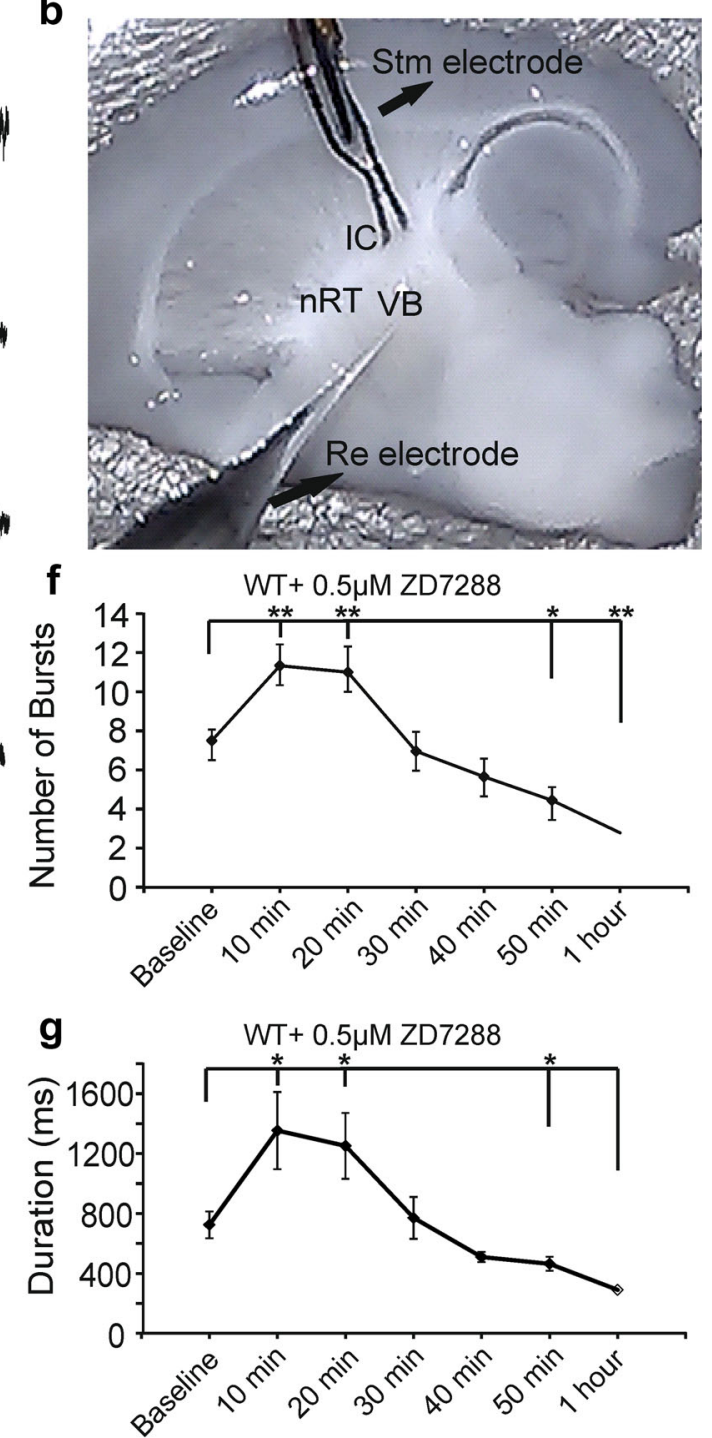

spikes during the burst activity between TRIP $8 \mathrm{~b}^{-1-}$ and WT mice (Student's $t$ tests, $* * *$ indicates $p<0.001$ ). e Shorter duration of stimulus-induced burst activity in TRIP8 $\mathrm{b}^{-1-}$ compared to WT mice (Student's $t$ tests, *** indicates $p<0.001$ ). $\mathbf{f}$ and $\mathbf{g}$ Bath application of $0.5 \mu \mathrm{M}$ ZD7288-induced time-dependent effects on intrathalamic network activity (Repeated-measures ANOVAs followed by Student's $t$ tests, $n=6$ mice, *, **, *** indicate $\mathrm{p}<0.05, p<0.01$, and $p<0.001$, respectively. Each data point was compared to the value before ZD7288 application (no ZD7288))

neurons generated spontaneous burst activity with a frequency of $4.2 \mathrm{~Hz}(n=9$ trials; Fig. $9 \mathrm{~b}) . I_{\mathrm{h}}$ properties in $\mathrm{TC}$ neurons were then set to simulate the combinations of $I_{\mathrm{h}}$ conductance, $V_{0.5}, k$ and activation kinetics observed in TRIP8 $^{-1-}$ neurons ( $n=10$ trials; Fig. 9c) as obtained in voltage-clamp recordings. Since TRIP8b is not expressed in GABAergic neurons of the $n R T$, the properties of $n R T$ cells were not changed in the model. Compared to WT, the frequency of intrathalamic network oscillations based on 
a

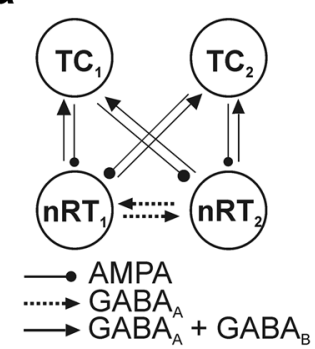

d

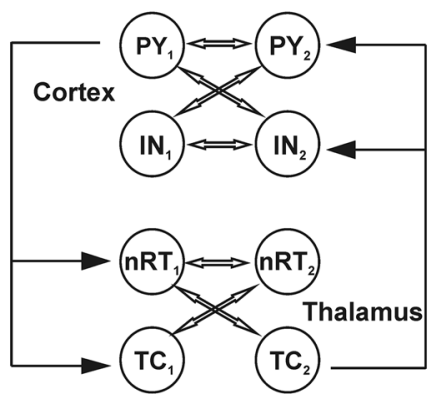

e

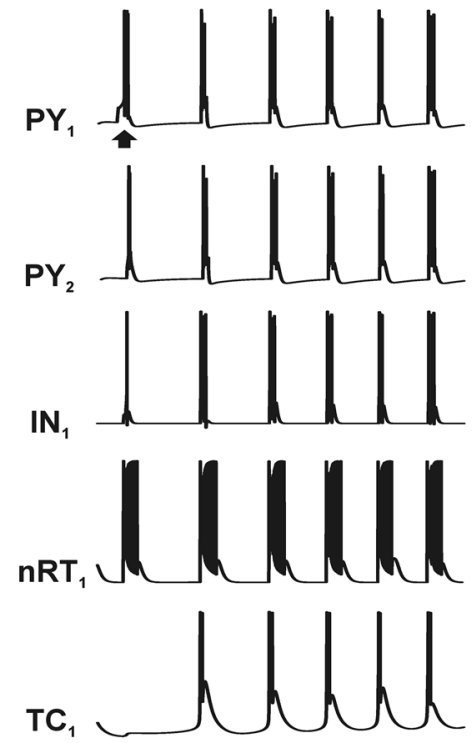

b nRT UMN

C
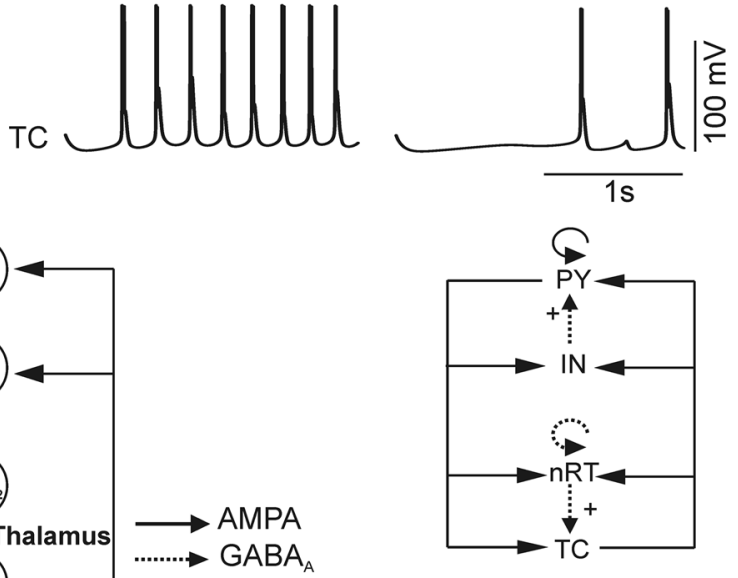

$f$
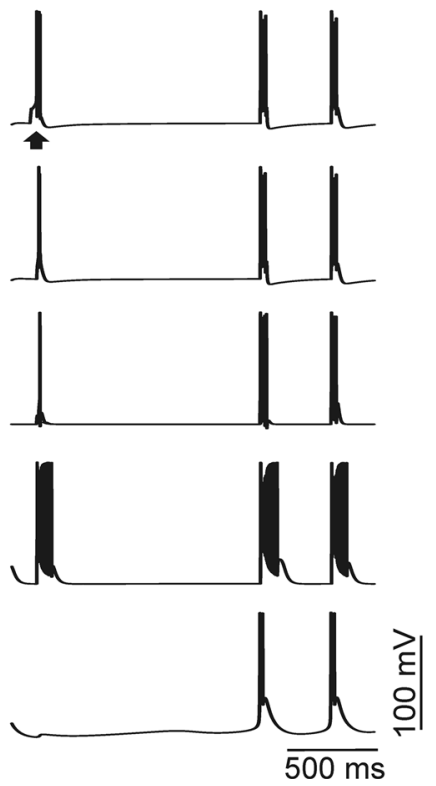

significantly slower compared to WT (b) conditions (Student's $t$ test, $p<0.05$ ). d The network topology as well as the connection parameters correspond to Destexhe (Destexhe et al. 1998). Four cell types were used in this simulation. PY, IN, TC and nRT stand for cortical pyramidal neuron, cortical interneurons, thalamocortical cells and reticular thalamic neurons, respectively. e Oscillations were initiated by electrical stimulation of one pyramidal neuron (PY1) indicated by arrows. Actual $I_{\mathrm{h}}$ parameters obtained from PY and TC neurons of WT (e) and TRIP8b $\mathrm{b}^{-1}$ (f) mice under voltage-clamp conditions were used for the simulation. At $-70 \mathrm{mV}$, oscillations occurred at a slower frequency range in TRIP8b ${ }^{-1-}$ compared to WT conditions (Student's $t$ test, $p<0.05$ )

rhythmic network activity was generated, and in another run just one burst was generated, while all runs with WT parameters resulted in sustained rhythmic activity. 
In the eight-cell model (Fig. 9d-f), oscillations were evoked by electrical stimulation of one cortical pyramidal cell (PY1). When the $I_{\mathrm{h}}$ modules of cortical pyramidal and TC neurons were parameterized with values obtained from WT neurons, the network displayed oscillations with a frequency of about $4 \mathrm{~Hz}$ and all cell types discharged in one phase of a cycle. Simulation of thalamocortical network oscillations using $I_{\mathrm{h}}$ parameters obtained from $\mathrm{TRIP} \mathrm{b}^{-/-}$mice for cortical pyramidal and TC neurons showed significantly slower oscillatory activity in a frequency range of about $2 \mathrm{~Hz}(n=6$ trials for both WT and TRIP8b $^{-1-}$, Student's $t$ test, $\left.p<0.01\right)$.

These data indicate that the alterations of $I_{\mathrm{h}}$ induced by the knockout of TRIP8b lead to the slowing of thalamocortical network activity towards delta frequency.

\section{Discussion}

The present study sought to understand the functional role of TRIP8b in the thalamocortical system by combining expression analysis, in vitro and in vivo electrophysiological approaches, in both wild-type (WT) and TRIP8b knockout (TRIP8b ${ }^{-/-}$) mice, as well as computer simulation of thalamocortical activity. TRIP8 $\mathrm{b}^{-1-}$ mice exhibited reduced expression of $\mathrm{HCN}$ channels and $I_{\mathrm{h}}$ current density leading to hyperpolarized RMP of TC neurons and altered firing properties. Reduced $I_{\mathrm{h}}$ in the thalamocortical system of TRIP8b ${ }^{-1-}$ mice was associated with altered oscillatory activity and increased delta frequency neuronal activity in horizontal slices, mathematical models, and in animals during episodes of active-wakefulness. TRIP8b $\mathrm{b}^{-1-}$ mice also exhibited suppression of the normal desynchronization of thalamocortical oscillations at the transition from slowwave sleep to wakefulness. These findings identify TRIP8b as a necessary molecule which contributes to EEG desynchronization and TRIP8b deficiency as a likely explanation for thalamocortical dysrhythmia, a perturbation of normal thalamocortical activity that has been observed in various neuropsychiatric disorders including schizophrenia and depression (Llinás et al. 1999; Schulman et al. 2011).

\section{Contribution of TRIP8b to the HCN channel function in TC neurons of different thalamic nuclei}

A major function of TRIP8b in the mammalian brain is the regulation of HCN channel trafficking and surface localization (Lewis et al. 2009; Piskorowski et al. 2011; Santoro et al. 2009). In line with previous studies of the hippocampus (Lewis et al. 2011) and VB thalamus (Heuermann et al. 2016), we found a strong downregulation of $I_{h}$ in $\mathrm{TRIP}^{-1-} \mathrm{TC}$ neurons due to reduced $\mathrm{HCN}$ channel protein expression. Here, we extend this finding by demonstrating that TRIP8b upregulates $I_{h}$ in several functionally different thalamic areas: $\mathrm{dLGN}$, the primary relay for visual information; VB and $\mathrm{PO}$, which form complementary somatosensory pathways with distinct inputs and targets (Kleinfeld and Deschênes 2011); and CM, involved in arousal and attention (Schiff et al. 2013). The fine-tuning of TC neuron properties within these different nuclei which is mandatory to suit their respective roles in the thalamocortical network is influenced by the variations in $I_{\mathrm{h}}$ density, HCN subunit composition, and specific contribution(s) of TRIP8b. It is interesting to note that TRIP8b is not expressed in GABAergic thalamic neurons, namely nRT neurons and local circuit interneurons (Heuermann et al. 2016; present study, see Supplemental Figure $5 \mathrm{a}-\mathrm{c}$ ). The preserved $I_{\mathrm{h}}$ in these cells may partially explain the infrequent absence seizures (Heuermann et al. 2016) and short bursts of activity in our LFP recordings in $\mathrm{TRIP} \mathrm{b}^{-1-}$ mice, as compared to the severe epileptic phenotype of HCN2 knockouts (Ludwig et al. 2003).

$\mathrm{HCN}$ channels are partially open at rest and thus critically contribute to the RMP and $R_{\text {in }}$ in TC neurons. Knockout of HCN2 (Ludwig et al. 2003; Huang et al. 2009; Budde et al. 2012; Meuth et al. 2006), HCN4 (Budde et al. 2012), or pharmacological blockade of $I_{h}$ (Leist et al. 2016) shifts the RMP to more hyperpolarized potentials. Similarly, we found that downregulating $I_{\mathrm{h}}$ by knocking out TRIP8b produced a robust - $11 \mathrm{mV}$ shift in RMP in TC neurons, accompanied by a $45 \%$ increase in $R_{\text {in }}$. We further demonstrated that these changes in membrane properties have pronounced effects on the firing properties of TC neurons in TRIP8b ${ }^{-1-}$ mice, increasing the propensity for burst firing in response to depolarizing inputs but preventing rebound bursts following injection of hyperpolarizing currents. Due to the hyperpolarized RMP and lack of $I_{\mathrm{h}}$-dependent afterdepolarizing potential (see Fig. 5, right upper panel) that occurs in WT cells, TRIP8b ${ }^{-1-}$ neurons remain below the threshold for activating $\mathrm{T}$-type $\mathrm{Ca}^{2+}$ channels, which are responsible for the generation of the rebound burst. Notably, injection of hyperpolarizing current from a holding potential of $-60 \mathrm{mV}$ (which is above the threshold for activating T-type $\mathrm{Ca}^{2+}$ channels) resulted in the reappearance of rebound bursts in TRIP8b ${ }^{-1-}$ TC cells, suggesting that neuromodulatory influences could potentially restore this capability in vivo. Rebound bursting is important for different physiological and pathophysiological oscillatory activity within the thalamocortical network, particularly sleep spindles, delta oscillations and perhaps also spike-wave discharges (SWDs), mediated by reciprocal innervation between nRT and TC neurons (Steriade 2003).

In addition to alterations in burst firing, TRIP8 $\mathrm{b}^{-1-} \mathrm{TC}$ neurons showed a significant reduction in tonic AP firing upon injection of depolarizing current steps compared to WT animals. Extracellular application of $10 \mu \mathrm{M}$ ZD7288 
to WT TC neurons had a similar effect, as has been observed before in thalamic, hypothalamic and DRG neurons (Leist et al. 2016; Momin et al. 2008; Cai et al. 2012). This is in contrast to results in cortical and hippocampal pyramidal neurons, in which loss of $I_{h}$ enhances AP firing (Huang et al. 2009; Lewis et al. 2011). This discrepancy may result from differences in HCN subunit expression and subcellular localization, causing the tonic depolarizing influence of $I_{\mathrm{h}}$ to be more important in some neurons (e.g., TC neurons), whereas the effect on $R_{\text {in }}$ dominates in others (pyramidal neurons). Another notable finding is that the reduction in the number of APs induced by ZD7288 was less extensive compared to TRIP8b knockout animals, even after restoring the RMP to $-60 \mathrm{mV}$ with $\mathrm{DC}$ current injection. These results indicate that there might be additional mechanisms underlying the reduction of AP firing in TC cells of TRIP8b ${ }^{-1-}$ mice. Possible mechanisms may be related to the decreased cAMP levels and/or alterations in $\mathrm{K}^{+}$channel function in TRIP8b ${ }^{-1-}$ mice. Since increases in cAMP enhance tonic firing in rodent TC neurons (Ehling et al. 2013) the lower basal cAMP level in TRIP8b ${ }^{-/-}$mice brain compared to WT might contribute to the reduction of AP firing in TC cells in these animals. Another possible candidate is changes in Kv1.2 channels, which have been shown to increase their amplitude upon co-expression with TRIP8b (Santoro et al. 2009). Since Kv1.2 channels are expressed in TC neurons (Decher et al. 2010) and Kv1.2deficient mice show decreased AP firing in neurons (Robinson et al. 2003), our results are in agreement with a reduction of current through Kv1.2 channels. Although no direct interaction was found between TRIP8b and channels underlying $I_{A}$ in central neuron (Santoro et al. 2009), this fast transient $\mathrm{K}^{+}$current is a potential candidate since it is modulated by cAMP and known to shape bursting and tonic firing of TC neurons (Pape et al. 1994; Kanyshkova et al. 2011). The voltage-dependent properties of $I_{\mathrm{A}}$ as described in the present study are well within the range of parameters found for activation $\left(\mathrm{V}_{\mathrm{h}}\right.$ : -14 to $\left.-37 \mathrm{mV}\right)$, inactivation $\left(\mathrm{V}_{\mathrm{h}}\right.$ : -65 to $\left.-82 \mathrm{mV}\right)$ and current kinetics ( $\tau_{\text {inact }}: 6$ to $96 \mathrm{~ms}$ ) of fast transient $\mathrm{K}^{+}$currents in $\mathrm{TC}$ neurons in different thalamic nuclei and species (Huguenard et al. 1991; Budde et al. 1992; Kanyshkova et al. 2011; McCormick 1991; Noh et al. 2011). In addition, a slow inactivating $I_{\mathrm{A}}$ component generating a large window current was described (McCormick 1991). The firing properties of TC neurons are influenced by $I_{\mathrm{A}}$ in several ways. The presence of a large $\mathrm{K}^{+}$current that generates a window current and is active at rest is expected to influence the RMP, bursting and tonic firing. Indeed computer modeling as well as pharmacological block by 4-amino pyridine (4-AP) revealed the hyperpolarizing influence of $I_{\mathrm{A}}$ on the RMP (McCormick 1991; Amarillo et al. 2014). Furthermore, electrophysiological recordings and computer simulations have demonstrated that $I_{\mathrm{A}}$ controls the generation, amplitude and duration of a LTS by functionally counteracting $I_{\mathrm{T}}$ (Huguenard et al. 1991; Pape et al. 1994; Amarillo et al. 2014; Gutierrez et al. 2001; Noh et al. 2010). Since $I_{\mathrm{A}}$ is active during repetitive bursting at the initial depolarizing phase of each cycle, the magnitude of the current influences the periodicity (Amarillo et al. 2014). While bursting requires hyperpolarized levels of the membrane potential, $I_{\mathrm{A}}$ also affects tonic firing from more depolarized potentials when $I_{\mathrm{T}}$ is inactivated. Since depolarizing inputs have to overcome the hyperpolarizing influence of the inactivating $I_{\mathrm{A}}$, the onset of firing is delayed thereby limiting the number of induced APs (McCormick 1991; Budde et al. 1992; Kanyshkova et al. 2011). Wash in of 4-AP abolishes the delayed onset of firing and increases the half width of single APs (Budde et al. 1992; Kanyshkova et al. 2011). While the latter decreases tonic firing frequencies, the total number of APs elicited by a given depolarizing pulse is increased, thus demonstrating the limitation of AP firing by $I_{\mathrm{A}}$. This view is corroborated by findings from different neuronal cell types where receptor stimulation-dependent activation and inhibition of $\mathrm{I}_{\mathrm{A}}$ reduces and increases the rate of firing APs, respectively (Kloppenburg et al. 1999; Pitra and Stern 2017). In a similar way the knock down of Kv4.1 channels increased neuronal firing rates (Hermanstyne et al. 2017).

Since several members of different $\mathrm{K}_{\mathrm{V}}$ channel subfamilies including $\mathrm{K}_{\mathrm{V}} 1.4, \mathrm{~K}_{\mathrm{V}} 3.3, \mathrm{~K}_{\mathrm{V}} 3.4, \mathrm{~K}_{\mathrm{V}} 4.1-4.3$ reveal typical $I_{A}$ properties, the molecular basis of fast transient $\mathrm{K}^{+}$currents is complex (Song 2002). This complexity is even increased by the formation of multi-protein ion channel complexes that underlie native currents. In case of $I_{A}$, the $\mathrm{K}_{\mathrm{V}}$ channel-interacting proteins (KChIPs) and dipeptidyl peptidase-like proteins (DPLPs) interact with the pore-forming $\alpha$-subunits (Jerng and Pfaffinger 2014). Based on expression studies and analysis of native current, combinations of $\mathrm{K}_{\mathrm{V}} 4.2 / \mathrm{K}_{\mathrm{V}} 4.3$, KChIP3/KChIP4, and DPP6/DPP10 may contribute to $\mathrm{I}_{\mathrm{A}}$ in thalamic TC neurons (Serôdio and Rudy 1998; Rhodes et al. 2004; Xiong et al. 2004; Wang et al. 2014; Kanyshkova et al. 2011).

Based on the functional properties and expression profile of transient $\mathrm{K}^{+}$channels discussed above, a number of alterations found in TRIP8b ${ }^{-1-}$ mice may be attributed to the reduction in cAMP and consequent changes in $I_{\mathrm{A}}$. Channels based on the combination of $\mathrm{K}_{\mathrm{V}} 4.2$ and KChiP3 have been shown to undergo a rightward shift in the activation curve and slowing of inactivation kinetics following cAMP-dependent modulation (Schrader et al. 2002). Therefore, the leftward shift in the $I_{\mathrm{A}}$ activation curve and the faster inactivation kinetics are in line with the decreased cAMP levels found in TRIP8b ${ }^{-/-}$mice. Additional interactions with DPP6 may result in the hyperpolarizing shift of the inactivation curve in TRIP8b ${ }^{-1-}$ mice 
(Jerng and Pfaffinger 2014). Together these changes enlarge the window current, increase the tonically active $I_{\mathrm{A}}$ near the RMP and increase the voltage-activated $I_{\mathrm{A}}$ close to the AP threshold (Kloppenburg et al. 1999). In combination with the reduction in $I_{\mathrm{h}}$, increased tonic $I_{\mathrm{A}}$ hyperpolarizes the RMP (Amarillo et al. 2014) and reduces tonic firing by delaying the onset of firing and reducing the number of evoked APs. When an LTS is evoked in TC neurons of $\mathrm{TRIP} \mathrm{b}^{-1-}$ mice the enlarged $I_{\mathrm{A}}$ is shaping the time course by contributing to reduced amplitude and duration. In addition, the combined changes in $I_{\mathrm{A}}$ and $I_{\mathrm{h}}$ may help to sustain oscillatory LTS generation at low frequency. While a decreased $I_{\mathrm{h}}$ is expected to promote oscillations, conditions of imposed hyperpolarization may further facilitate oscillatory activity (Amarillo et al. 2014). With respect to thalamocortical oscillations, it is interesting to note that the block of $\mathrm{I}_{\mathrm{A}}$ by 4-AP elicited spontaneous field potential activity in thalamocortical slices in vitro (D'Arcangelo et al. 2002). While sequences of fast (10-16 Hz) and slower (5-9 Hz) field potential bursts were recorded in WAG/Rij rats, a rodent absence epilepsy model (van Luijtelaar and Zobeiri 2014), only fast oscillations were seen in non-epileptic control rats. SWDs in the frequency range of 7-9 Hz are characteristic for a number of rodent absence epilepsy models. Therefore, the increased $I_{\mathrm{A}}$ window current may hinder the transition from slow oscillations to faster epilepsy-related SWDs and wake-related rhythms.

\section{TRIP8b regulates the cAMP sensitivity of $I_{h}$ in TC neurons}

In addition to affecting surface expression, TRIP8b regulates gating and cAMP-sensitivity of HCN channels (Lewis et al. 2009; Santoro et al. 2009; Zolles et al. 2009; Hu et al. 2013; Saponaro et al. 2014). Previous in vitro studies have demonstrated that TRIP8b is an allosteric inhibitor for cAMP binding (Hu et al. 2013; Saponaro et al. 2014; Deberg et al. 2015), and interaction of TRIP8b with the CNBD antagonizes the effects of cAMP on channel gating (i.e., induces a negative shift in $V_{0.5}$ and slows down activation kinetics). In accordance with the antagonizing effects of TRIP8b on cAMP and similar to a previous report (Heuermann et al. 2016), we found a significant increase in the sensitivity and efficacy of cAMP in TC neurons in TRIP8b ${ }^{-1-}$ mice compared to WT animals. Unexpectedly, $V_{0.5}$ values of $I_{h}$ in $\mathrm{TRIP} \mathrm{b}^{-1-} \mathrm{TC}$ neurons in the present study were significantly more hyperpolarized compared to WT cells, and channel activation was slower. Since HCN channels in rodent TC neurons have been shown to be controlled by basal cAMP production (Wainger et al. 2001; Pape 1996; Kanyshkova et al. 2009), the negative shift in the activation curve of $I_{\mathrm{h}}$ and its slower activation kinetics pointed to possible changes in cAMP signaling in TRIP8b $\mathrm{b}^{-/-}$mice. In fact, reduced cAMP levels were determined in brain tissue samples from TRIP8b ${ }^{-1-}$ mice compared to WT animals. Along these lines, the adenylyl cyclase blocker SQ22536 and the A1 receptor agonist CCPA both shifted the activation curve of $I_{\mathrm{h}}$ to more hyperpolarized potentials in WT neurons. Of note, Heuermann et al. (2016) found no difference in basal $V_{0.5}$ values between WT and TRIP8b ${ }^{-1-}$ TC neurons. An intriguing possibility to explain this discrepancy may be that the coronal slices used here better preserve ascending neuromodulatory inputs (e.g., hypothalamic histaminergic projections) that were severed in horizontal slices used in the previous study. If this were the case, it might obscure differences in basal cAMP levels and thus $V_{0.5}$ during slice recordings.

\section{TRIP8b regulates $I_{h}$ in cortical pyramidal neurons}

Previous studies demonstrated a high expression level of TRIP8b in layer $\mathrm{V}$ cortical pyramidal neurons with an expression gradient similar to HCN1 channels (Santoro et al. 2004). In these cells, TRIP8b is responsible for the trafficking of HCN1 subunits to the cell membrane. In TRIP8 $\mathrm{b}^{-l-}$ mice, the lack of TRIP8b in cortical pyramidal neurons resulted in a reduction in the expression of HCN1/ 2 subunits in the somatosensory cortex whereas the mRNA levels were not affected. In accordance with these results, layer V and VI cortical pyramidal neurons of TRIP8b ${ }^{-1-}$ mice showed a significantly lower $I_{\mathrm{h}}$ density compared to WT animals. The reduction of $I_{\mathrm{h}}$ in cortex is responsible for an increased $R_{\text {in }}$ and a concomitant increase in dendritic excitability in these neurons. In fact, the downregulation of $I_{\mathrm{h}}$ in cortical pyramidal neurons has been reported in several types of pathophysiological conditions including absence epilepsy (Huang et al. 2009; Phillips et al. 2014; Heuermann et al. 2016; Kole et al. 2007). However, in contrast to the previous study by Heuermann et al. (2016), our in vivo LFP recordings from the somatosensory cortex of $\mathrm{TRIP} \mathrm{b}^{-1-}$ mice revealed only sporadic short $(<1 \mathrm{~s})$ epileptiform-like activity in a small number of animals. No definite reason for the differences between the two studies can be named except a potential genetic drift, especially in a small founder colony (Sade et al. 2014). It has been noted before that differences in epilepsy severity between different colonies of GEARS rats that were derived from the same founder colony may be based on environmental conditions and/or genetic drift (Powell et al. 2014). Early life environmental experience can influence the frequency of SWD occurrence in adulthood (van Luijtelaar and Sitnikova 2006). In WAG/Rij rats, maternal deprivation and neonatal handling from postnatal day 1 to 21 reduced the number of SWDs in adulthood (4.5 months of age) with about $35 \%$, while the mean duration was not affected (Schridde et al. 2006). In addition, introducing an enriched 
environment (for 2 months from 1 to 3 months of age) was found to have no effect on the number of animals with SWDs and no effect on the number of SWDs, only on the mean duration of SWDs (Schridde and van Luijtelaar 2004). In addition, cross-fostered WAG/Rij pups which were raised by Wistar mothers showed fewer SWDs compared to the condition in which they were cross-fostered within the WAG/Rij strain (Sitnikova et al. 2016). Altogether, these data suggest that environmental factors play a role in shaping the occurrence of SWDs in WAG/Rij rats, but not to a very large extent and especially not for the number of animals that show SWDs. Earlier manipulations (postnatal) seem to play a larger effect than post-weaning manipulations regarding the number and mean duration of SWDs. After comparing the environmental conditions in which the two groups of TRIP8b $\mathrm{b}^{-1-}$ mice were raised, we found some minor differences (e.g., differences in light/dark cycle and hygienic procedures, but not general handling) that might to some degree affect the occurrence of SWDs in our TRIP8b ${ }^{-1-}$ mice colony.

\section{The role of TRIP8b in regulation of thalamocortical oscillations and modulation of delta oscillations}

In the present study, we demonstrated that the dysregulation of $I_{\mathrm{h}}$ in the thalamocortical system of TRIP8b $\mathrm{b}^{-/-}$mice is associated with altered thalamocortical oscillations, revealing a significant increase in slow oscillations in the delta frequency range during episodes of active-wakefulness and reduced desynchronization of the EEG during transitions from slow-wave sleep to active-wakefulness. Considering that the behavior during active-wakefulness of TRIP8b ${ }^{-1-}$ mice did not appear qualitatively and quantitatively (as was established in the open field test (Lewis et al. 2011)) different from that of WT, it is safe to exclude that the differences in EEG between the mice strains is due to differences in overt behavior. More general, the appearance of prominent delta waves during wake is associated with both physiological and pathological conditions. In the cognitive domain, increased delta frequency oscillations are implicated in attention and salience detection and subliminal perception (Knyazev 2012). However, increased baseline delta power has also been associated with a range of neurological disorders including Alzheimer's disease (Jeong 2004; Babiloni et al. 2009), and schizophrenia (Boutros et al. 2008). Interestingly, while $\mathrm{TRIP} \mathrm{b}^{-/-}$mice were largely phenotypically normal during initial behavioral screening (Lewis et al. 2011), they did exhibit significantly impaired nest building, an established endophenotype for schizophrenia (Amann et al. 2010), raising the possibility that reduced thalamocortical $\mathrm{HCN}$ channel function may recapitulate some features of this disorder.
Several neurotransmitter systems contribute to promotion of sleep and wakefulness and regulation of cortical activation during different behavioral states. Both thalamus and neocortex receive a large number of cholinergic projections from pontine and midbrain reticular formation, as well as cholinergic (and non-cholinergic) inputs from nuclei in the basal forebrain (BF) activating system (Buzsaki et al. 1988). These cholinergic projections play an important role in the desynchronized EEG typical for wakefulness and REM sleep (Wikler 1952; Steriade et al. 1990). In addition, the serotonergic neurons of the dorsal raphe (DR) and noradrenergic neurons of the locus coeruleus (LC) contribute to both pathways and directly innervate cortical neurons (Brown et al. 2012). A number of observation point to a limited contribution of either TRIP8b or HCN channels to the function of these activating systems, thereby lowering the possibility that changes in the EEG of TRIP8b ${ }^{-1-}$ mice are related to alterations in these areas. In comparison to cortical and thalamic areas, the expression of TRIP8b was low in WT and expression of HCN2 was not altered following TRIP8b knock out in the ascending brainstem-activating system (see Supplemental Figures 10, 11). In addition, electrophysiological characterization of the cholinergic neurons of the $\mathrm{BF}$ and the locus coeruleus revealed only very little time-dependent anomalous rectification (Unal et al. 2012; Alreja and Aghajanian 1991; Hedrick and Waters 2010). Nevertheless, a role of activating systems in the aberrant waking EEG pattern in TRIP8b ${ }^{-1-}$ mice cannot be ruled out by the experiments presented here.

Several previous studies have established the importance of both thalamic and cortical $I_{h}$ in generating network oscillations, particularly delta and spindle oscillations during slow-wave sleep (Steriade et al. 1993; Steriade and Deschenes 1984; Crunelli et al. 2015; Kanyshkova et al. 2009). $I_{\mathrm{h}}$ in cortical pyramidal neurons helps to establish the subthreshold resonance frequency, typically in the theta band, which amplifies oscillations in this frequency range (Hu et al. 2002; Stark et al. 2013; Wahl-Schott and Biel 2009). Downregulation of $I_{\mathrm{h}}$ shifts the resonant frequency from the theta to delta range both within individual pyramidal neurons (Karameh et al. 2006; Stadler et al. 2014) and at the network level (Schmidt et al. 2016). We, therefore, conclude that the significant reduction of $I_{\mathrm{h}}$ in cortical pyramidal neurons of TRIP8b ${ }^{-1-}$ mice alters the preference of the cortical network in favor of slower oscillations.

$I_{\mathrm{h}}$ also contributes to delta rhythmicity at the level of the thalamus by promoting cycles of rebound bursts in reciprocally connected TC and nRT neurons (Crunelli et al. 2015; Steriade et al. 1993; Llinas and Steriade 2006; Steriade 2003; Timofeev and Bazhenov 2005; Kanyshkova et al. 2009; Meuth et al. 2003). Delta oscillations typical 
for slow-wave sleep occur due to hyperpolarization of TC neurons as sleep deepens, increasing the propensity for bursting (Steriade 2003; Llinas and Steriade 2006). Therefore, one might speculate that the hyperpolarized RMP of TC neurons in TRIP8b mice ${ }^{-1-}$, coupled with a cortical network that resonates at delta frequencies, favors generation of thalamocortical delta oscillations during active-wakefulness. However, impaired rebound bursting in these cells would prevent reverberant, runaway delta activity in the form of SWDs. In line with this hypothesis, our LFP recordings of intrathalamic network activity showed slowed inter-burst frequency in TRIP8b ${ }^{-1-}$ mice and a reduction in overall oscillatory activity. Interestingly, a low concentration of ZD7288 $(0.5 \mu \mathrm{M})$ generated timedependent effects, with an increase in rhythmic burst activity during the first $20 \mathrm{~min}$ after application followed by a significant decrease in rhythmic burst activity towards the end of recording that mimics the TRIP8 $\mathrm{b}^{-1-}$ condition. These findings suggest that the level of hyperpolarization and availability of $I_{\mathrm{h}}$ in thalamic neurons is an important determinant of the behavior of the thalamic network. Slight hyperpolarization is able to increase the rhythmic burst activity in thalamus (as may be the case in the epileptic $\mathrm{HCN} 2^{-1-}$ mouse), while further hyperpolarization (e.g., $\mathrm{TRIP} 8 \mathrm{~b}^{-1-} \mathrm{TC}$ neurons, with downregulation of both HCN2 and HCN4) can abolish or significantly slow down the intrathalamic network oscillations (Yue and Huguenard 2001). Slowing of oscillatory activity was also obtained after introducing the conductance levels, $V_{0.5}$ values and activation kinetics of $I_{\mathrm{h}}$ obtained from TRIP8b ${ }^{-1-}$ TC cells to thalamocortical network models (Destexhe et al. 1996). Further analyses with similar models will be an excellent tool for probing the graded effects of $I_{\mathrm{h}}$ within thalamocortical networks, and for guiding future experiments to understand the dynamic roles of HCN channels in modulating both physiological and pathophysiological brain states.

\section{Conclusion}

Here, we demonstrated an increase in delta rhythmicity within thalamocortical networks of TRIP8 $\mathrm{b}^{-/-}$mice during episodes of active-wakefulness resulting from reduced $I_{\mathrm{h}}$ (in combination with increased availability of $I_{\mathrm{A}}$ ) and consequently altered firing properties of TC neurons. Our results are consistent with a previous analysis of $I_{\mathrm{h}}$ in thalamic and cortical neurons of the TRIP8b ${ }^{-1-}$ mouse (Heuermann et al. 2016). Overall, the results obtained from TRIP8b $^{-1-}$ mice point to the importance of TRIP8b as a brain-specific HCN channel auxiliary subunit that regulates cellular and network oscillations. The interaction between TRIP8b and HCN channels seems to be necessary to prevent the occurrence of increased delta activity during wakefulness (thalamocortical dysrhythmia) thereby suggesting TRIP8b as a promising drug target (Han et al. 2015).

Authors' contributions TB designed and supervised the project, interpreted data, reviewed all experimental work and wrote the manuscript. MZ designed and performed experiments and analyzed data and wrote the manuscript. $\mathrm{RCH}$ performed experiments, analyzed data and did the mathematical modeling. MD performed experiments and analyzed data. GVL supervised the in vivo part of the experiments, interpreted data and wrote the manuscript. $\mathrm{AB}$ and $\mathrm{SB}$ performed cAMP quantification. $\mathrm{AB}$ wrote the manuscript. RJH, DMC. and HCP gave important intellectual and scientific input and provided material. $\mathrm{AL}$ and $\mathrm{VN}$ performed parts of the in vivo experiments. PM did data analysis. All authors revised the manuscript and approved the final version of the manuscript.

Acknowledgements The authors thank Elke Naß, Alexandra Markovic, Katrin Foraita, Julia Schröer and Svetlana Kiesling for excellent technical assistance. This work has been supported by Deutsches Forschungsgemeinschaft (DFG, BU 1019/15-1), Interdisziplinäres Zentrum für Klinische Forschung Münster (IZKF, Bud3/001/16) and National Institutes of Health (NIH) grants NS059934 and GM008152. Rahul Chaudhary and Maia Datunashvili were DAAD fellows. This work was done in partial fulfillment of the Ph.D. thesis of Mehrnoush Zobeiri.

\section{Compliance with ethical standards}

Conflict of interest The authors declare that they have no conflict of interest.

Open Access This article is distributed under the terms of the Creative Commons Attribution 4.0 International License (http://crea tivecommons.org/licenses/by/4.0/), which permits unrestricted use, distribution, and reproduction in any medium, provided you give appropriate credit to the original author(s) and the source, provide a link to the Creative Commons license, and indicate if changes were made.

\section{References}

Alreja M, Aghajanian GK (1991) Pacemaker activity of locus coeruleus neurons: whole-cell recordings in brain slices show dependence on cAMP and protein kinase A. Brain Res 556:339-343

Amann LC, Gandal MJ, Halene TB, Ehrlichman RS, White SL, McCarren HS, Siegel SJ (2010) Mouse behavioral endophenotypes for schizophrenia. Brain Res Bull 83:147-161. https://doi. org/10.1016/j.brainresbull.2010.04.008

Amarillo Y, Zagha E, Mato G, Rudy B, Nadal MS (2014) The interplay of seven subthreshold conductances controls the resting membrane potential and the oscillatory behavior of thalamocortical neurons. J Neurophysiol 112:393-410

Arain F, Zhou C, Ding L, Zaidi S, Gallagher MJ (2015) The developmental evolution of the seizure phenotype and cortical inhibition in mouse models of juvenile myoclonic epilepsy. Neurobiol Dis 82:164-175. https://doi.org/10.1016/j.nbd.2015. 05.016 
Babiloni C, Ferri R, Binetti G, Vecchio F, Frisoni GB, Lanuzza B, Miniussi C, Nobili F, Rodriguez G, Rundo F, Cassarino A, Infarinato F, Cassetta E, Salinari S, Eusebi F, Rossini PM (2009) Directionality of EEG synchronization in Alzheimer's disease subjects. Neurobiol Aging 30:93-102

Bista P, Cerina M, Ehling P, Leist M, Pape HC, Meuth SG, Budde T (2015a) The role of two-pore-domain background $\mathrm{K}^{+}$(K2P) channels in the thalamus. Pflugers Arch Eur J Physiol 467:895-905

Bista P, Pawlowski M, Cerina M, Ehling P, Leist M, Meuth P, Aissaoui A, Borsotto M, Heurteaux C, Decher N, Pape H-C, Oliver D, Meuth SG, Budde T (2015b) Differential phospholipase $\mathrm{C}$-dependent modulation of TASK and TREK two-pore domain $\mathrm{K}+$ channels in rat thalamocortical relay neurons. J Physiol 593:127-144

Boutros NN, Arfken C, Galderisi S, Warrick J, Pratt G, Iacono W (2008) The status of spectral EEG abnormality as a diagnostic test for schizophrenia. Schizophr Res 99:225-237

Broicher T, Seidenbecher T, Meuth P, Munsch T, Meuth SG, Kanyshkova T, Pape HC, Budde T (2007) T-current related effects of antiepileptic drugs and a $\mathrm{Ca}^{2+}$ channel antagonist on thalamic relay and local circuit interneurons in a rat model of absence epilepsy. Neuropharmacology 53:431-446

Brown RE, Basheer R, McKenna JT, Strecker RE, McCarley RW (2012) Control of sleep and wakefulness. Physiol Rev 92:1087-1187

Budde T, Mager R, Pape H-C (1992) Different types of potassium outward current in relay neurons acutely isolated from the rat lateral geniculate nucleus. Eur J Neurosci 4:708-722

Budde T, Caputi L, Kanyshkova T, Staak R, Abrahamczik C, Munsch $\mathrm{T}$, Pape H (2005) Impaired regulation of thalamic pacemaker channels through an imbalance of subunit expression in absence epilepsy. J Neurosci 25:9871-9882

Budde T, Kanyshkova T, Ehling P, Blaich A, Herrmann S, Ludwig A, Pape H-C (2012) Analysis of pacemaker currents in intralaminar and sensory thalamic nuclei. Acta Physiol 204(Suppl 689):040

Buzsaki G, Bickford RG, Ponomareff G, Thal LJ, Mandel R, Gage FH (1988) Nucleus basalis and thalamic control of neocortical activity in the freely moving rat. J Neurosci 8:4007-4026

Cai C, Meng X, He J, Wu H, Zou F (2012) Effects of ZD7288 on firing pattern of thermosensitive neurons isolated from hypothalamus. Neurosci Lett 506:336-341. https://doi.org/10.1016/j. neulet.2011.11.041

Cerina M, Szkudlarek HJ, Coulon P, Meuth P, Kanyshkova T, Nguyen XV, Göbel K, Seidenbecher T, Meuth SG, Pape H-C, Budde T (2015) Thalamic Kv 7 channels: pharmacological properties and activity control during noxious signal processing. Br J Pharmacol 172:3126-3140

Crunelli V, David F, Lorincz ML, Hughes SW (2015) The thalamocortical network as a single slow wave-generating unit. Curr Opin Neurobiol 31:72-80

Curró Dossi R, Nuñez A, Steriade M (1992) Electrophysiology of a slow $(0.5-4 \mathrm{~Hz})$ intrinsic oscillation of cat thalamocortical neurones in vivo. J Physiol 447:215-234

D'Arcangelo G, D'Antuono M, Biagini G, Warren R, Tancredi V, Avoli M (2002) Thalamocortical oscillations in a genetic model of absence seizures. Eur J Neurosci 16:2383-2393

Deberg HA, Bankston JR, Rosenbaum JC, Brzovic PS, Zagotta WN, Stoll S (2015) Structural mechanism for the regulation of HCN ion channels by the accessory protein TRIP8b. Structure 23:734-744

Decher N, Streit AK, Rapedius M, Netter MF, Marzian S, Ehling P, Renigunta V, Ko A, Dodel RC, Navarro-polanco RA, Preisig-mu R, Klebe G, Budde T, Baukrowitz T, Schlichthörl G, Craan T, Köhler A, Preisig-Müller R, Daut J (2010) RNA editing modulates the binding of drugs and highly unsaturated fatty acids to the open pore of Kv potassium channels. EMBO J 29:2101-2113

Destexhe A, Bal T, McCormick DA, Sejnowski TJ (1996) Ionic mechanisms underlying synchronized oscillations and propagating waves in a model of ferret thalamic slices. J Neurophysiol 76:2049-2070

Destexhe A, Contreras D, Steriade M (1998) Mechanisms underlying the synchronizing action of corticothalamic feedback through inhibition of thalamic relay cells. J Neurophysiol 79:999-1016

Ehling P, Cerina M, Meuth P, Kanyshkova T, Bista P, Coulon P, Meuth SG, Pape HC, Budde T (2013) $\mathrm{Ca}^{2+}$-dependent large conductance $\mathrm{K}^{+}$currents in thalamocortical relay neurons of different rat strains. Pflugers Arch Eur J Physiol 465:469-480

Felix R, Sandoval A, Sánchez D, Gómora JC, De la Vega-Beltrán JL, Treviño CL, Darszon A (2003) ZD7288 inhibits low-threshold $\mathrm{Ca}(2+)$ channel activity and regulates sperm function. Biochem Biophys Res Commun 311:187-192

Gutierrez C, Cox CL, Rinzel J, Sherman SM (2001) Dynamics of low-threshold spike activation in relay neurons of the cat lateral geniculate nucleus. J Neurosci 21:1022-1032

Han Y, Lyman K, Clutter M, Schiltz GE, Ismail Q-A, Prados DB, Luan C-H, Chetkovich DM (2015) Identification of smallmolecule inhibitors of hyperpolarization-activated cyclic nucleotide-gated channels. J Biomol Screen 20:1124-1131. https://doi. org/10.1177/1087057115589590

He C, Chen F, Li B, Hu Z (2014) Neurophysiology of HCN channels: from cellular functions to multiple regulations. Prog Neurobiol 112:1-23

Hedrick T, Waters J (2010) Physiological properties of cholinergic and non-cholinergic magnocellular neurons in acute slices from adult mouse nucleus basalis. PLoS ONE 5:e11046

Hermanstyne TO, Granados-Fuentes D, Mellor RL, Herzog ED, Nerbonne JM (2017) Acute Knockdown of Kv4.1 Regulates repetitive firing rates and clock gene expression in the suprachiasmatic nucleus and daily rhythms in locomotor behavior. ENEURO 4:0377-0416

Herrmann S, Stieber J, Ludwig A (2007) Pathophysiology of HCN channels. Pflugers Arch Eur J Physiol 454:517-522

Heuermann RJ, Jaramillo TC, Ying S-W, Suter BA, Lyman KA, Han Y, Lewis AS, Hampton TG, Shepherd GMG, Goldstein PA, Chetkovich DM (2016) Reduction of thalamic and cortical Ih by deletion of TRIP8b produces a mouse model of human absence epilepsy. Neurobiol Dis 85:81-92. http://linkinghub.elsevier. com/retrieve/pii/S0969996115300632

Hines ML, Carnevale NT (2001) Neuron: a tool for neuroscientists. Neuroscientist 7:123-135

Hu H, Vervaeke K, Storm JF (2002) Two forms of electrical resonance at theta frequencies, generated by M-current, h-current and persistent $\mathrm{Na}^{+}$current in rat hippocampal pyramidal cells. J Physiol 545:783-805

Hu L, Santoro B, Saponaro A, Liu H, Moroni A, Siegelbaum S (2013) Binding of the auxiliary subunit TRIP8b to HCN channels shifts the mode of action of cAMP. J Gen Physiol 142:599-612

Huang Z, Walker MC, Shah MM (2009) Loss of dendritic HCN1 subunits enhances cortical excitability and epileptogenesis. J Neurosci 29:10979-10988

Huang Z, Lujan R, Martinez-Hernandez J, Lewis AS, Chetkovich DM, Shah MM (2012) TRIP8b-independent trafficking and plasticity of adult cortical presynaptic HCN1 channels. J Neurosci 32:14835-14848

Huber R, Deboer T, Tobler I (2000) Topography of EEG dynamics after sleep deprivation in mice. J Neurophysiol 84:1888-1893

Huguenard JR, Coulter DA, Prince DA (1991) A fast transient potassium current in thalamic relay neurons: kinetics of activation and inactivation. J Neurophysiol 66:1304-1315

Jeong J (2004) EEG dynamics in patients with Alzheimer's disease. Clin Neurophysiol 115:1490-1505

Jerng HH, Pfaffinger PJ (2014) Modulatory mechanisms and multiple functions of somatodendritic A-type $\mathrm{K}^{+}$channel auxiliary subunits. Front Cell Neurosci 8:82 
Kanyshkova T, Pawlowski M, Meuth P, Dube C, Bender RA, Brewster AL, Baumann A, Baram TZ, Pape H-C, Budde T (2009) Postnatal expression pattern of $\mathrm{HCN}$ channel isoforms in thalamic neurons: relationship to maturation of thalamocortical oscillations. J Neurosci 29:8847-8857. https://doi.org/10.1523/ JNEUROSCI.0689-09.2009

Kanyshkova T, Broicher T, Meuth SG, Pape H-C, Budde T (2011) A-type $\mathrm{K}^{+}$currents in intralaminar thalamocortical relay neurons. Pflugers Arch 461:545-556

Kanyshkova T, Meuth P, Bista P, Liu Z, Ehling P, Caputi L, Doengi M, Chetkovich DM, Pape HC, Budde T (2012) Differential regulation of $\mathrm{HCN}$ channel isoform expression in thalamic neurons of epileptic and non-epileptic rat strains. Neurobiol Dis 45:450-461. https://doi.org/10.1016/j.nbd.2011.08.032

Kanyshkova T, Ehling P, Cerina M, Meuth P, Zobeiri M, Meuth SG, Pape HC, Budde T (2014) Regionally specific expression of high-voltage-activated calcium channels in thalamic nuclei of epileptic and non-epileptic rats. Mol Cell Neurosci 61:110-122

Karameh FN, Dahleh MA, Brown EN, Massaquoi SG (2006) Modeling the contribution of lamina 5 neuronal and network dynamics to low frequency EEG phenomena. Biol Cybern 95:289-310

Kirchhof P, Tal T, Fabritz L, Klimas J, Nesher N, Schulte JS, Ehling P, Kanyshkova T, Budde T, Nikol S, Fortmueller L, Stallmeyer B, Müller FU, Schulze-Bahr E, Schmitz W, Zlotkin E, Kirchhefer U (2015) First report on an inotropic peptide activating tetrodotoxin-sensitive, \&quot;neuronal\&quot; sodium currents in the heart. Circ Heart Fail 8:79-88

Kleinfeld D, Deschênes M (2011) Neuronal basis for object location in the vibrissa scanning sensorimotor system. Neuron 72:455-468

Kloppenburg P, Levini RM, Harris-Warrick RM (1999) Dopamine modulates two potassium currents and inhibits the intrinsic firing properties of an identified motor neuron in a central pattern generator network. J Neurophysiol 81:29-38

Knyazev GG (2012) EEG delta oscillations as a correlate of basic homeostatic and motivational processes. Neurosci Biobehav Rev 36:677-695. https://doi.org/10.1016/j.neubiorev.2011.10.002

Kole MHP, Bräuer AU, Stuart GJ (2007) Inherited cortical HCN1 channel loss amplifies dendritic calcium electrogenesis and burst firing in a rat absence epilepsy model. J Physiol 578:507-525

Leist M, Datunashvilli M, Kanyshkova T, Zobeiri M, Aissaoui A, Cerina M, Romanelli MN, Pape H-C, Budde T (2016) Two types of interneurons in the mouse lateral geniculate nucleus are characterized by different h-current density. Sci Rep 6:24904

Lewis AS, Schwartz E, Chan CS, Noam Y, Shin M, Wadman WJ, Surmeier DJ, Baram TZ, Macdonald RL, Chetkovich DM (2009) Alternatively spliced isoforms of TRIP8b differentially control $h$ channel trafficking and function. J Neurosci 29:6250-6265

Lewis AS, Vaidya SP, Blaiss CA, Liu Z, Stoub TR, Brager DH, Chen X, Bender RA, Estep CM, Popov AB, Kang CE, Van Veldhoven PP, Bayliss DA, Nicholson DA, Powell CM, Johnston D, Chetkovich DM (2011) Deletion of the hyperpolarization-activated cyclic nucleotide-gated channel auxiliary subunit TRIP8b impairs hippocampal $\mathrm{I}_{\mathrm{h}}$ localization and function and promotes antidepressant behavior in mice. J Neurosci 31:7424-7440

Llinas RR, Steriade M (2006) Bursting of thalamic neurons and states of vigilance. J Neurophysiol 95:3297-3308

Llinás RR, Ribary U, Jeanmonod D, Kronberg E, Mitra PP (1999) Thalamocortical dysrhythmia: a neurological and neuropsychiatric syndrome characterized by magnetoencephalography. Proc Natl Acad Sci USA 96:15222-15227

Ludwig A, Budde T, Stieber J, Moosmang S, Wahl C, Holthoff K, Langebartels A, Wotjak C, Munsch T, Zong X, Feil S, Feil R, Lancel M, Chien KR, Konnerth A, Pape H-C, Biel M, Hofmann
F (2003) Absence epilepsy and sinus dysrhythmia in mice lacking the pacemaker channel HCN2. EMBO J 22:216-224

McCormick DA (1991) Functional properties of a slowly inactivating potassium current in guinea pig dorsal lateral geniculate relay neurons. J Neurophysiol 66:1176-1189

McCormick DA, Bal T (1997) SLEEP AND AROUSAL: thalamocortical Mechanisms. Annu Rev Neurosci 20:185-215

McCormick DA, Huguenard JR (1992) A model of the electrophysiological properties of thalamocortical relay neurons. J Neurophysiol 68:1384-1400

McCormick DA, Pape HC (1990) Properties of a hyperpolarizationactivated cation current and its role in rhythmic oscillation in thalamic relay neurones. J Physiol 431:291-318

Meuth SG, Budde T, Kanyshkova T, Broicher T, Munsch T, Pape H-C (2003) Contribution of TWIK-related acid-sensitive $\mathrm{K}^{+}$channel 1 (TASK1) and TASK3 channels to the control of activity modes in thalamocortical neurons. J Neurosci 23:6460-6469

Meuth P, Meuth SG, Jacobi D, Broicher T, Pape H, Budde T (2005) Get the rhythm: modeling neuronal activity. J Undergr Neurosci Educ 4:1-11

Meuth SG, Kanyshkova T, Meuth P, Landgraf P, Munsch T, Ludwig A, Hofmann F, Pape HC, Budde T (2006) Membrane resting potential of thalamocortical relay neurons is shaped by the interaction among TASK3 and HCN2 channels. J Neurophysiol 96:1517-1529

Momin A, Cadiou H, Mason A, McNaughton PA (2008) Role of the hyperpolarization-activated current $\mathrm{I}_{\mathrm{h}}$ in somatosensory neurons. J Physiol 586:5911-5929

Noh J, Choi H-J, Chung J-M (2010) $\mathrm{Zn}^{2+}$ enhances the intrinsic bursting activity of a rat thalamic relay neuron. Neurosci Res 67:95-97

Noh J, Chang SY, Wang SY, Chung JM (2011) Dual function of $\mathrm{Zn}^{2+}$ on the intrinsic excitability of dopaminergic neurons in rat substantia nigra. Neuroscience 175:85-92

Pape BYH (1992) Adenosine promotes burst activity in guinea-pig geniculocortical neurons through two different ionicmechanisms. J Physiol 477:729-753

Pape HC (1996) Queer current and pacemaker: the hyperpolarizationactivated cation current in neurons. Annu Rev Physiol 58:299-327

Pape HC, Budde T, Mager R, Kisvárday ZF (1994) Prevention of $\mathrm{Ca}^{2+}$-mediated action potentials in GABAergic local circuit neurones of rat thalamus by a transient $\mathrm{K}^{+}$current. J Physiol 478(Pt 3):403-422

Phillips AM, Kim T, Vargas E, Petrou S, Reid CA (2014) Spike-andwave discharge mediated reduction in hippocampal HCN1 channel function associates with learning deficits in a genetic mouse model of epilepsy. Neurobiol Dis 64:30-35. https://doi. org/10.1016/j.nbd.2013.12.007

Piskorowski R, Santoro B, Siegelbaum SA (2011) TRIP8b splice forms act in concert to regulate the localization and expression of HCN1 channels in CA1 pyramidal neurons. Neuron 70:495-509

Pitra S, Stern JE (2017) A-type $\mathrm{K}^{+}$channels contribute to the prorenin increase of firing activity in hypothalamic vasopressin neurosecretory neurons. Am J Physiol Heart Circ Physiol 313:H548-H557

Powell KL, Tang H, Ng C, Guillemain I, Dieuset G, Dezsi G, Çarçak N, Onat F, Martin B, O’Brien TJ, Depaulis A, Jones NC (2014) Seizure expression, behavior, and brain morphology differences in colonies of genetic absence epilepsy rats from strasbourg. Epilepsia 55:1959-1968

Rhodes KJ, Carroll KI, Sung MA, Doliveira LC, Monaghan MM, Burke SL, Strassle BW, Buchwalder L, Menegola M, Cao J, An WF, Trimmer JS (2004) KChIPs and Kv4 alpha subunits as integral components of A-type potassium channels in mammalian brain. J Neurosci 24:7903-7915 
Robinson RB, Siegelbaum SA (2003) Hyperpolarization-activated cation currents: from molecules to physiological function. Annu Rev Physiol 65:453-480

Sade Y, Kara NZ, Toker L, Bersudsky Y, Einat H, Agam G (2014) Beware of your mouse strain; differential effects of lithium on behavioral and neurochemical phenotypes in Harlan ICR mice bred in Israel or the USA. Pharmacol Biochem Behav 124:36-39. https://doi.org/10.1016/j.pbb.2014.05.007

Sánchez-Alonso JL, Halliwell JV, Colino A (2008) ZD 7288 inhibits T-type calcium current in rat hippocampal pyramidal cells. Neurosci Lett 439:275-280

Santoro B, Wainger BJ, Siegelbaum SA (2004) Regulation of HCN channel surface expression by a novel C-terminal protein-protein interaction. J Neurosci 24:10750-10762

Santoro B, Piskorowski RA, Pian P, Hu L, Liu H, Siegelbaum SA (2009) Article TRIP8b splice variants form a family of auxiliary subunits that regulate gating and trafficking of $\mathrm{HCN}$ channels in the brain. Neuron 62:802-813. https://doi.org/10.1016/j.neuron.2009.05.009

Saponaro A, Pauleta SR, Cantini F, Matzapetakis M, Hammann C, Donadoni C, Hu L, Thiel G, Banci L, Santoro B, Moroni A (2014) Structural basis for the mutual antagonism of cAMP and TRIP8b in regulating HCN channel function. Proc Natl Acad Sci USA 111:14577-14582

Schiff ND, Shah SA, Hudson AE, Nauvel T, Kalik SF, Purpura KP (2013) Gating of attentional effort through the central thalamus. J Neurophysiol 109:1152-1163

Schmidt SL, Dorsett CR, Iyengar AK, Fröhlich F (2016) Interaction of intrinsic and synaptic currents mediate network resonance driven by layer $\mathrm{v}$ pyramidal cells. $1-15$

Schrader LA, Anderson AE, Mayne A, Pfaffinger PJ, Sweatt JD (2002) PKA modulation of Kv4.2-encoded A-type potassium channels requires formation of a supramolecular complex. J Neurosci 22:10123-10133

Schridde U, van Luijtelaar G (2004) The influence of strain and housing on two types of spike-wave discharges in rats. Genes Brain Behav 3:1-7

Schridde U, Strauss U, Bräuer AU, van Luijtelaar G (2006) Environmental manipulations early in development alter seizure activity, $I_{\mathrm{h}}$ and $\mathrm{HCN} 1$ protein expression later in life. Eur $\mathrm{J}$ Neurosci 23:3346-3358

Schulman JJ, Cancro R, Lowe S, Lu F, Walton KD, Llinás RR, De Ridder D (2011) Imaging of thalamocortical dysrhythmia in neuropsychiatry. 5:1-11

Serôdio P, Rudy B (1998) Differential expression of Kv4 K ${ }^{+}$channel subunits mediating subthreshold transient $\mathrm{K}^{+}$(A-type) currents in rat brain. J Neurophysiol 79:1081-1091

Sherman SM (2005) Thalamic relays and cortical functioning. Prog Brain Res 149:107-126

Sherman SM, Guillery RW (2002) The role of the thalamus in the flow of information to the cortex. Philos Trans R Soc Lond B Biol Sci 357:1695-1708

Sitnikova E, Rutskova EM, Raevsky VV (2016) Maternal care affects EEG properties of spike-wave seizures (including pre- and postictal periods) in adult WAG/Rij rats with genetic predisposition to absence epilepsy. Brain Res Bull 127:84-91

Song WJ (2002) Genes responsible for native depolarization-activated $\mathrm{K}^{+}$currents in neurons. Neurosci Res 42:7-14

Stadler K, Bierwirth C, Stoenica L, Battefeld A, Reetz O, Mix E, Schuchmann S, Velmans T, Rosenberger K, Bräuer AU, Lehnardt S, Nitsch R, Budt M, Wolff T, Kole MHP, Strauss U (2014) Elevation in type i interferons inhibits HCN1 and slows cortical neuronal oscillations. Cereb Cortex 24:199-210

Stark E, Eichler R, Roux L, Fujisawa S, Rotstein HG (2013) Inhibition-induced theta resonance in cortical circuits. 2:1263-1276
Steriade M (2003) The corticothalamic system in sleep. Front. Biosci. 8:878-899

Steriade M, Deschenes M (1984) The thalamus as a neuronal oscillator. Brain Res Rev 8:1-63

Steriade M, Datta S, Paré D, Oakson G, Curró Dossi RC (1990) Neuronal activities in brain-stem cholinergic nuclei related to tonic activation processes in thalamocortical systems. J Neurosci 10:2541-2559

Steriade M, McCormick DA, Sejnowski TJ (1993) Thalamocortical oscillations in the sleeping and aroused brain. Science 262:679-685

Timofeev I, Bazhenov M (2005) Trends in chronobiology research In: Columbus. F (ed) Nova Science Publishers, Inc, Newyork

Unal CT, Golowasch JP, Zaborszky L (2012) Adult mouse basal forebrain harbors two distinct cholinergic populations defined by their electrophysiology. Front Behav Neurosci 6:21

van Calker D, Müller M, Hamprecht B (1979) Adenosine regulates via two different types of receptors, the accumulation of cyclic amp in cultured brain cells. J Neurochem 33:999-1005

van Luijtelaar G, Sitnikova E (2006) Global and focal aspects of absence epilepsy: The contribution of genetic models. 30:983-1003

van Luijtelaar G, Zobeiri M (2014) Progress and outlooks in a genetic absence epilepsy model (WAG/Rij). Curr Med Chem 21:704-721

van Luijtelaar G, Wilde M, Citraro R, Scicchitano F, van Rijn C (2012) Does antiepileptogenesis affects sleep in genetic epileptic rats? Int J Psychophysiol 85:49-54. https://doi.org/10.1016/j. ijpsycho.2011.09.010

Wahl-Schott C, Biel M (2009) HCN channels : structure, cellular regulation and physiological function. Cell Mol life Sci 66:470-494

Wainger BJ, Degennaro M, Santoro B, Siegelbaum SA, Tibbs GR (2001) Molecular mechanism of cAMP modulation of HCN pacemaker channels. Nature 411:805-810

Wang W, Kim HJ, Lee J-H, Wong V, Sihn C-R, Lv P, Perez Flores MC, Mousavi-Nik A, Doyle KJ, Xu Y, Yamoah EN (2014) Functional significance of $\mathrm{K}^{+}$channel $\beta$-subunit KCNE3 in auditory neurons. J Biol Chem 289:16802-16813

Wemhöner K, Kanyshkova T, Silbernagel N, Fernandez-Orth J, Bittner S, Kiper A, Rinné S, Netter M, Meuth S, Budde T, Decher N (2015) An N-terminal deletion variant of HCN1 in the epileptic WAG/Rij strain modulates HCN current densities. Front Mol Neurosci 8:63

Wikler A (1952) Pharmacologic dissociation of behavior and EEG "sleep patterns" in dogs; morphine, n-allylnormorphine, and atropine. Proc Soc Exp Biol Med 79:261-265

Wu X, Liao L, Liu X, Luo F, Yang T, Li C (2012) Is ZD7288 a selective blocker of hyperpolarization-activated cyclic nucleotide-gated channel currents? Channels 6:438-442

Xiong H, Kovacs I, Zhang Z (2004) Differential distribution of KChIPs mRNAs in adult mouse brain. Brain Res Mol Brain Res 128:103-111

Yue BW, Huguenard JR (2001) The role of H-current in regulating strength and frequency of thalamic network oscillations. Thalamus Relat. Syst. 1:95-103

Zolles G, Wenzel D, Bildl W, Schulte U, Hofmann A, Müller CS, Thumfart JO, Vlachos A, Deller T, Pfeifer A, Fleischmann BK, Roeper J, Fakler B, Klöcker N (2009) Association with the auxiliary subunit PEX5R/Trip8b controls responsiveness of $\mathrm{HCN}$ channels to cAMP and adrenergic stimulation. Neuron 62:814-825 